\title{
Evidence that depletion of the sorting nexin 1 by siRNA promotes HGF-induced MET endocytosis and MET phosphorylation in a gefitinib-resistant human lung cancer cell line
}

\author{
YUKIO NISHIMURA $^{1}$, SOICHI TAKIGUCHI ${ }^{2}$, SHIGERU ITO ${ }^{3}$ and KAZUYUKI ITOH $^{4}$ \\ ${ }^{1}$ Division of Pharmaceutical Cell Biology, Graduate School of Pharmaceutical Sciences, Kyushu University, \\ Fukuoka 812-8582; ${ }^{2}$ Institute for Clinical Research, National Kyushu Cancer Center, Fukuoka 811-1395; \\ ${ }^{3}$ Institute of Biomaterials and Bioengineering, Tokyo Medical and Dental University, Tokyo 101-0062; \\ ${ }^{4}$ Department of Biology, Osaka Medical Center for Cancer and Cardiovascular Diseases, Osaka 537-8511, Japan
}

Received September 11, 2013; Accepted October 22, 2013

DOI: $10.3892 /$ ijo.2013.2194

\begin{abstract}
The receptor tyrosine kinase MET and its ligand HGF are known to be overexpressed in malignant tumor cells, and they have been implicated in gefitinib resistance in lung cancer cells. We recently found that sorting nexin 1 (SNX1), a protein that interacts with EGFR, exhibited negative regulation of EGFR trafficking out of early to late endosomes in gefitinibresistant NSCLC cell lines. To investigate the role of SNX1 on HGF-stimulated MET endocytosis and its downregulation via the early/late endocytic pathway, we examined the effect of depletion of SNX1 expression by siRNA in NSCLC cells. Using immunofluorescence, we found that the silencing of SNX1 by siRNA caused a dramatic change in the intracellular distribution of plasma membrane-associated MET and that the resultant MET staining was spread throughout the cytoplasm, and it co-localized well with the endocytosed Texas red-labeled transferrin in the siRNA-SNX1-transfected cells. We also found efficient MET phosphorylation and rapid endocytic delivery of phosphorylated MET from early endosomes to late endosomes in the siRNA-SNX1-transfected cells. By contrast, the siRNA-control transfected cells showed inefficient endocytic delivery of phosphorylated MET from early endosomes
\end{abstract}

Correspondence to: Dr Yukio Nishimura, Division of Pharmaceutical Cell Biology, Graduate School of Pharmaceutical Sciences, Kyushu University, 3-1-1 Maidashi, Higashi-ku, Fukuoka 812-8582, Japan

E-mail: ynkio443@gmail.com

Abbreviations: SNX1, sorting nexin 1; HGF, hepatocyte growth factor; pMET, phosphorylated MET; EGFR, epidermal growth factor receptor; pEGFR, phosphorylated epidermal growth factor receptor; NSCLC, non-small cell lung cancer

Key words: sorting nexin 1, hepatocyte growth factor, MET, phosphorylated MET, epidermal growth factor receptor, endocytosis, endosomes/lysosomes, gefitinib, non-small cell lung cancer cell lines to late endosomes. Furthermore, large amounts of phosphorylated MET that had accumulated in late endosomes were seen even after $60 \mathrm{~min}$ of HGF-stimulation in the presence of bafilomycin A1, indicating that degradation of phosphorylated MET proceeds in a late endosome/lysosome pathway. Western blot analysis revealed that depletion of SNX1 by siRNA induced a maximal and dramatic increase in phosphorylated MET at $60 \mathrm{~min}$, followed by an accelerated degradation of phosphorylated MET after HGF stimulation in the cells. Taken together, we suggest that SNX1 plays a suppressive role in the regulation of $\mathrm{HGF}$-stimulated MET/phosphorylated MET endocytosis and downregulation via the early/late endocytic pathway in the gefitinib-resistant NSCLC cells.

\section{Introduction}

The MET receptor tyrosine kinase is expressed in a variety of normal and malignant cells (1-3). Many studies have reported that MET is overexpressed in a variety of cancers and that MET overexpression could be the result of the MET proto-oncogene amplification, which is notably observed in transcriptional activation (4), a small subset of cancers (5-8), and has recently seen in lung cancers $(9,10)$. The signaling pathway of MET receptor tyrosine kinase and its ligand, hepatocyte growth factor (HGF) (11), has been shown to play an important role in increased cell proliferation, reduced apoptosis, altered cytoskeletal function, increased metastasis and other biologic responses $(12,13)$. Like other receptor tyrosine kinases (RTKs), upon HGF binding, MET dimerizes and autophosphorylates, creating active docking sites for proteins that mediate downstream signaling leading to the activation of pathways such as MAPK, PI3K-AKT and the STAT signaling pathway (14-16). Thus, MET activation produces a variety of biological responses that lead to increased cell growth, cell motility, cell invasion and angiogenesis, as well as anti-apoptotic effects. After MET activation, HGF-MET complexes are internalized via clathrin-coated vesicles and delivered to the early endosomal tubulovesicular compartment 
commonly referred to as the sorting endosome. In the sorting endosome, ubiquitinated receptors can be recognized by the endosomal sorting complex required for transport (ESCRT) machinery that generates multivesicular bodies (MVBs) by packaging cargo into small vesicles that bud off from the limiting membrane into the lumen of the endosomes (17). This sorting pathway terminates HGF/MET signaling by delivering receptors to the lysosomes for degradation, a process known as downregulation (18). Alternatively, MET is recycled to the plasma membrane by endosomal recycling pathways.

The EGFR tyrosine kinase inhibitors (EGFR-TKIs), gefitinib and erlotinib, have been shown to block the signal transduction pathways implicated in the proliferation and survival of cancer cells (19-22). These EGFR-TKIs are effective in treating non-small cell lung cancers (NSCLCs) that have activating mutations in the EGFR gene $(23,24)$. Most EGFR mutant NSCLCs initially respond to EGFR inhibitors; however, most of these tumors ultimately become resistant to the drug treatment. Engelman et al have previously demonstrated that amplification of MET induces gefitinib resistance by driving ERBB3 (HER3)-dependent activation of PI3K, a pathway thought to be specific to EGFR/ERBB family receptors in lung cancer (9). However, the mechanisms that contribute to gefitinib resistance in the remaining tumors are unknown.

We reported previously that an aberration in certain steps of EGF-EGFR/phosphorylated EGFR(pEGFR) endocytic trafficking from the early endosomes to the late endosomes/lysosomes occurs in the gefitinib-resistant $E G F R$ wild-type NSCLC cells, whereas endocytosis of $\mathrm{EGFR} / \mathrm{pEGFR}$ is normal in gefitinib-sensitive EGFR mutant NSCLC cells $(25,26)$. We also made the novel observation that large amounts of sorting nexin 1 (SNX1) are localized in the aggregated vesicular structures of early endosomes where the internalized pEGFR is also accumulated (27). Furthermore, we have recently reported that silencing of endogenous SNX1 by siRNA stimulates endocytosis and the ligand-induced downregulation of EGFR/pEGFR, while increasing of $\mathrm{pEGFR}$ protein expression in gefitinib-resistant cells (28). Thereby, we postulate that SNX1 plays a negative role in the regulation of EGF-dependent downregulation of EGFR and its phosphorylation via the early/late endocytic pathway in human lung cancer cells.

SNX1 is a family of sorting nexin proteins, of which approximately 25 human sorting nexins have been identified so far (29). They have previously been demonstrated to interact with EGFR (30), and are localized to early endosomes through their phospholipid-binding motifs termed as the phox homology (PX) domain (29). Previous studies have also revealed that SNX1 overexpression causes enhanced EGFR degradation, and that deletion mutants of SNX1 blocked EGFR degradation but fail to inhibit receptor endocytosis $(30,31)$. Therefore, it was suggested that SNX1 interacts with EGFR and enhances the degradation of the receptor upon EGF stimulation, thereby implying that SNX1 plays a role in endosome-lysosome trafficking. However, recent evidence has failed to support the intracellular co-localization of SNX1 with EGFR and its direct role in EGFR degradation, raising the possibility that alternative mechanisms are involved in the function of SNX1 $(32,33)$. The detailed function of SNX1 regulating endocytic trafficking of transmembrane tyrosine kinase receptors remains unclear.

In the present study, we analyzed the intracellular regulatory function of SNX1 with regard to HGF-induced endocytosis and the downregulation of MET/phosphorylated MET (pMET) by using confocal immunofluorescence microscopy, western blot analysis, and RNAi-mediated knockdown approaches in gefitinib-resistant NSCLC cell lines. We demonstrated that silencing of endogenous SNX1 by siRNA stimulates efficient endocytosis of HGF-induced MET and pMET in gefitinib-resistant NSCLC cells. We further found that depletion of SNX1 stimulates the ligand-induced downregulation of MET/pMET, while increasing of pMET protein expression in gefitinib-resistant cells. Therefore, we postulate that SNX1 plays a suppressive role in the regulation of HGF-dependent downregulation of MET and its phosphorylation via the early/late endocytic pathway in human lung cancer cells.

\section{Materials and methods}

Materials. Texas red-labeled EGF, Texas red-labeled human transferrin and SlowFade anti-fade reagent were purchased from Molecular Probes (Eugene, OR, USA). Recombinant human HGF and EGF were purchased from PeproTech (London, UK). Bafilomycin A1, cycloheximide (CHX), and DAPI were obtained from Sigma (St. Louis, MO, USA). Other chemicals were of reagent grade and were obtained from commercial sources.

Cell culture. Cell lines PC9 and A549 (National Kyushu Cancer Center, Fukuoka, Japan) were cultured in RPMI-1640 supplemented with $10 \%$ fetal bovine serum (FBS). Cells were maintained under standard cell culture conditions at $37^{\circ} \mathrm{C}$ and $5 \% \mathrm{CO}_{2}$ in a humid environment.

Small interfering RNA. siRNA targeting SNX1 was purchased from Dharmacon (Boulder, CO, USA). The target sequence of the siRNA was as follows: 5'-AAGAACAAGACCAAGA GCCAC-3'. Scramble sequence was used as a control. The two NSCLC cell lines were transfected with Lipofectamine 2000 (Life Technologies, Gaithersburg, MD, USA) in the presence of $40 \mathrm{nM}$ siRNA targeting SNX1 according to the manufacturer's protocol. Knockdown efficiency was determined by qRT-PCR and confocal immunofluorescence microscopy analysis.

$q R T-P C R$ analysis. The NSCLC PC9 or A549 cells transfected with siRNA-control or siRNA-SNX1 were stimulated with EGF $(100 \mathrm{ng} / \mathrm{ml})$ at $37^{\circ} \mathrm{C}$ for 5,15 or $30 \mathrm{~min}$, and total RNA was extracted from each cell line using an RNeasy RNA isolation kit (Qiagen, Hilden, Germany) according to the manufacturer's instructions. Transcription into cDNA was done in a 20- $\mu$ l volume using ThermoScript RT-PCR System with random hexamer (Invitrogen, Carlsbad, CA, USA) according to the manufacturer's instructions. All PCR reactions were carried out in a final volume of $25 \mu \mathrm{l}$ and were performed in the ABI PRISM 7000 Sequence Detection System (Applied Biosystems, Foster City, CA, USA) according to the manufacturer's protocol. Sequence-specific primers were quoted from an official website 'PrimerBank' (http://pga.mgh.harvard.edu/ primerbank/) for the indicated genes (Table I). The reaction 
Table I. Primers for qRT-PCR for human MET and $\beta$-actin.

\begin{tabular}{lc}
\hline PCR primer & Nucleotide sequence \\
\hline MET & \\
Forward & 5'-TGGTGCAGAGGAGCAATGG-3' \\
Reverse & 5'-CATTCTGGATGGGTGTTTCCG-3' \\
$\beta$-actin & \\
Forward & 5'-CATGTACGTTGCTATCCAGGC-3' \\
Reverse & 5'-CTCCTTAATGTCACGCACGAT-3' \\
\hline
\end{tabular}

mix consisted of SYBR Premix Ex Taq (2X) (Takara Bio, Shiga, Japan) $12.5 \mu 1$, ROX Reference Dye (50X) (Takara Bio) $0.5 \mu \mathrm{l}, 0.2 \mu \mathrm{M}$ of each specific forward and reverse primer, and $9 \mu \mathrm{l}$ of diluted cDNA (equivalent to $0.03-2.85 \mathrm{ng}$ of total RNA). Amplifications were done under standard conditions (10 sec at $95^{\circ} \mathrm{C}$ followed by 40 cycles of $5 \mathrm{sec}$ at $95^{\circ} \mathrm{C}$ and $31 \mathrm{sec}$ at $60^{\circ} \mathrm{C}$ ). The number of PCR cycles needed to reach the fluorescence threshold was determined in triplicate for each cDNA, averaged and then normalized to a reference gene ( $\beta$-actin). A standard curve was generated with serial 3 -fold dilutions of a representative cDNA. For all assays tested, the PCR reaction was linear over the range studied (20-40 cycles of amplification). All RT-PCR reactions gave a single band when analyzed by gel electrophoresis.

Antibodies. Alexa 488-labeled goat anti-mouse and goat anti-rabbit secondary antibodies were obtained from Molecular Probes. Normal rabbit IgG and normal mouse monoclonal IgG1 were purchased from Imgenex (San Diego, CA, USA) and Angio-proteomie (Boston, MA, USA), respectively. Normal goat serum was purchased from Sigma. Mouse monoclonal antibody to SNX1 was purchased from BD Biosciences (San Jose, CA, USA). Anti-MET, pMET, EGFR, pEGFR and LAMP1 antibodies were obtained from Cell Signaling Technology (Beverly, MA, USA), and anti- $\beta$-actin antibody was obtained from Sigma. Mouse monoclonal anti-HGF $\alpha$-chain antibody was purchased from Institute of Immunology (Tokyo, Japan). Anti-cathepsin D was affinity-purified by protein A Sepharose CL-4B (Sigma), followed by immunoaffinity chromatography using antigen-conjugated Sepharose 4B as described previously $(34,35)$.

\section{Immunofluorescence microscopy}

General procedures. Immunofluorescence microscopy was described previously (25-28). The A549 cells were grown for 2 days on glass coverslips in 6-well plates in RPMI-1640 with $10 \%$ fetal bovine serum. Cells were fixed with $3.7 \%$ formaldehyde in phosphate-buffered saline (PBS), $\mathrm{pH} 7.4$, permeabilized in PBS containing $0.1 \%$ saponin. After washing with PBS, cells were blocked with PBS-10\% normal goat serum. All subsequent antibody and wash solutions contained $0.1 \%$ saponin. The A549 cells were incubated with specific primary antibodies (mouse monoclonal anti-HGF $\alpha$-chain antibody, mouse monoclonal anti-LAMPI antibody, mouse monoclonal anti-EGFR antibody or mouse monoclonal anti-SNX1 antibody), for $1 \mathrm{~h}$, followed by washes with PBS containing $0.1 \%$ saponin and incubation for $1 \mathrm{~h}$ with the secondary antibodies at $20 \mu \mathrm{g} / \mathrm{ml}$. Each cell line was stained with DAPI to reveal nuclei. Controls for antibody specificity were non-immune normal mouse IgG1 or non-immune normal rabbit IgG. To label early endosomes, cells were incubated with RPMI-1640 without FBS for $3 \mathrm{~h}$ at $37^{\circ} \mathrm{C}$ followed by $20 \mathrm{~min}$ incubation in culture medium containing Texas red-conjugated transferrin, and then cells were fixed and double-stained for MET with anti-MET monoclonal antibody or EGFR with anti-EGFR antibody. Late endosomes/lysosomes were stained with anti-LAMP1 antibody, since the LAMP1 protein is distributed within endocytic organelles and is at its highest concentration in the late endosomes/lysosomes, as observed for other lysosomal glycoproteins, namely, lysosomal-associated membrane protein-1 (LAMP-1) and LAMP-2 $(36,37)$. The distribution of the labeled proteins was then analyzed by confocal immunofluorescence microscopy of the fixed cells. Slides were mounted with SlowFade anti-fade reagent and observed on a Zeiss LSM 510 META confocal laser scanning microscope (Carl Zeiss, Oberkochen, Germany), equipped with krypton/argon laser sources. Co-localization of MET or EGFR and Texas red-labeled transferrin, HGF $\alpha$-chain and cathepsin D, or pMET and LAMP1 was quantified using Image $\mathbf{J}$ software and the MacSCOPE X software (Mitani Corporation, Osaka, Japan).

Treatment of the cells with HGF. In order to clarify MET internalization, we followed the uptake of HGF with time in each cell line. To minimize the contribution of recycling and/ or lysosomal degradation of the internalized HGF, we quantified the HGF uptake in each cell type for time periods of up to $30 \mathrm{~min}$. At $48 \mathrm{~h}$ transfection, A549 cells treated with siRNAcontrol or siRNA-SNX1 were starved for $12 \mathrm{~h}$ with RPMI-1640 without FBS at $37^{\circ} \mathrm{C}$ and the cells were incubated in the presence of Texas red-transferrin in prewarmed medium, and the serum-starved cells were then incubated with HGF $(100 \mathrm{ng} / \mathrm{ml})$ at $37^{\circ} \mathrm{C}$ for 15 or $30 \mathrm{~min}$, and the distribution of internalized HGF stained with anti-HGF $\alpha$-chain antibody and lysosomes stained with anti-cathepsin D antibody was then assessed by confocal immunofluorescence microscopy. In some cases, cells were starved for $3 \mathrm{~h}$ with RPMI-1640 without FBS at $37^{\circ} \mathrm{C}$ and then the phosphorylation of MET was induced with HGF (100 $\mathrm{ng} / \mathrm{ml})$ for $15 \mathrm{~min}$ on ice in binding medium $(1 \mathrm{mg} / \mathrm{ml}$ BSA in RPMI-1640 medium). The cells were then rinsed with ice-cold PBS, incubated in the presence of Texas red-transferrin in prewarmed medium, and chased at $37^{\circ} \mathrm{C}$ for 15 or $30 \mathrm{~min}$. The fixed cells were double-stained for pMET with anti-pMET antibody and LAMP1 with anti-LIMP1 antibody.

Western blot analysis. Protein samples were separated by sodium dodecyl sulfate (SDS)-polyacrylamide gel electrophoresis (PAGE) and then transferred to polyvinylidene difluoride membranes (Millipore, Billerica, MA, USA). Following blocking, the membrane was blotted with the appropriate antibody, and subsequently, horseradish peroxidase-conjugated anti-mouse or anti-rabbit IgG (GE Healthcare Bioscience, Tokyo, Japan) was applied. The final signal was revealed by ECL chemiluminescence (Pierce, Rockford, IL, USA). Digital images were analyzed with NIH Image software to measure the density of each band without a saturated signal.

HGF-stimulates phosphorylated MET degradation. The A549 cells were starved for $12 \mathrm{~h}$ with RPMI-1640 without FBS at $37^{\circ} \mathrm{C}$. 

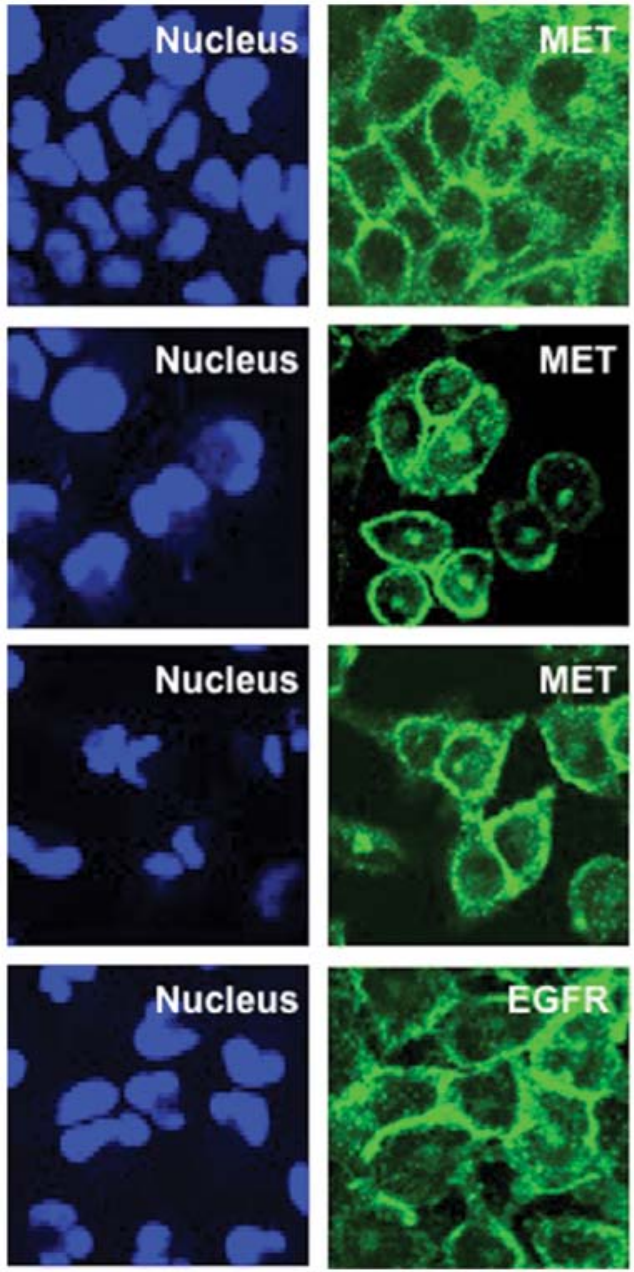
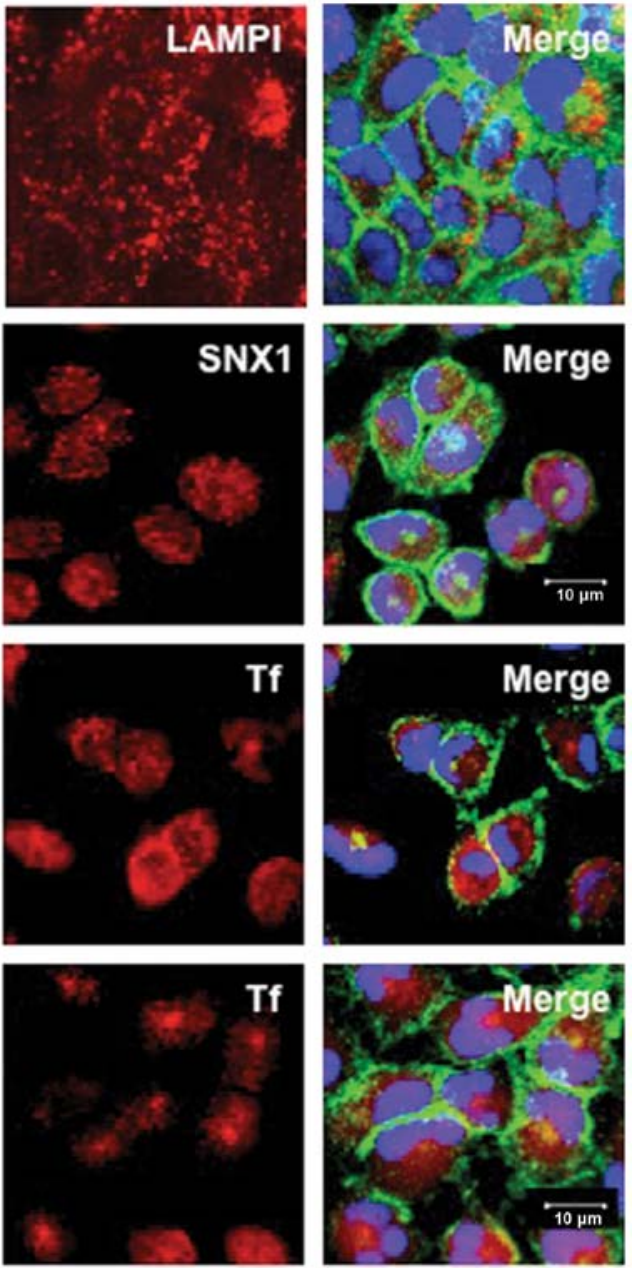

Figure 1. Intracellular distribution of MET and EGFR in the gefitinib-resistant A549 cells. The A549 cells were fixed and double-stained for MET (green) and LAMP1 (red), MET (green) and SNX1 (red), or MET (green) and the endocytosed Texas red-labeled transferrin (red) as described in Materials and methods. Cells were also double-stained for EGFR (green) and the endocytosed Texas red-labeled transferrin (red). Superimposed images of MET or EGFR and each organelle marker protein are shown. Each cell line was stained with DAPI (blue) to reveal the nuclei. In A549 cells, MET is exclusively localized in the plasma membrane at a cell-cell contact sites, however, no colocalization with organelle marker proteins such as LAMP1, SNX1 or transferrin is observed, suggesting that MET is mainly associated with plasma membrane, but not with the early endosomes or late endosomes in A549 cells. EGFR is also localized in the plasma membrane, and is not associated with the early endosomes in A549 cells. Bar, $10 \mu \mathrm{m}$.

The serum-starved cells were then preincubated for $30 \mathrm{~min}$ in the presence of CHX $(20 \mu \mathrm{g} / \mathrm{ml})$ before incubation with HGF $(100 \mathrm{ng} / \mathrm{ml})$ at $37^{\circ} \mathrm{C}$ for the indicated times. The cells were then washed with ice-cold-PBS and lysed, followed by SDS-PAGE and western blot analysis. Bafilomycin A1 $(0.17 \mu \mathrm{M})$ was added when the cells were incubated with RPMI-1640.

Statistical analysis. Data are expressed as mean \pm SD unless otherwise noted. Significance $(\mathrm{p}<0.05)$ was determined by using Student's t-test, since the data met all the assumptions for parametric statistical analysis.

\section{Results}

Intracellular distribution of MET in a gefitinib-resistant NSCLC cell line. To examine the intracellular distribution of MET in a gefitinib-resistant cell line, A549 cells were fixed and double-labeled with antibodies specific to MET and lysosomal integral membrane protein (LAMP1) or SNX1. We determined the intracellular distribution of late endosomes/lysosomes by using antibody specific to LAMP1 that is distributed within endocytic organelles and is at the highest concentration in the late endosomes/lysosomes, as observed for other lysosomal glycoproteins $(36,37)$. In addition, to examine the intracellular distribution of MET with endocytosed transferrin, a marker of early endosomes, Texas red-labeled transferrin was applied to the cells for $20 \mathrm{~min}$. After transferrin binds to its receptor on the cell surface, it is internalized via clathrin-coated vesicles and is subsequently delivered to the early endosomes. Confocal immunofluorescence microscopy studies showed that MET was mostly seen to be associated with plasma membranes, and that MET-positive staining was not co-localized with SNX1- or transferrin-positive early endosomes or with LAMP1-positive late endosomes/lysosomes (Fig. 1). Furthermore, to analyze the intracellular distribution of EGFR, the cells were fixed and double-labeled with antibody to EGFR and the endocytosed Texas red-labeled transferrin, and then the intracellular distribution of EGFR was examined. The results showed that most EGFR staining was mainly distributed in the 


\section{A MET/SNX1}
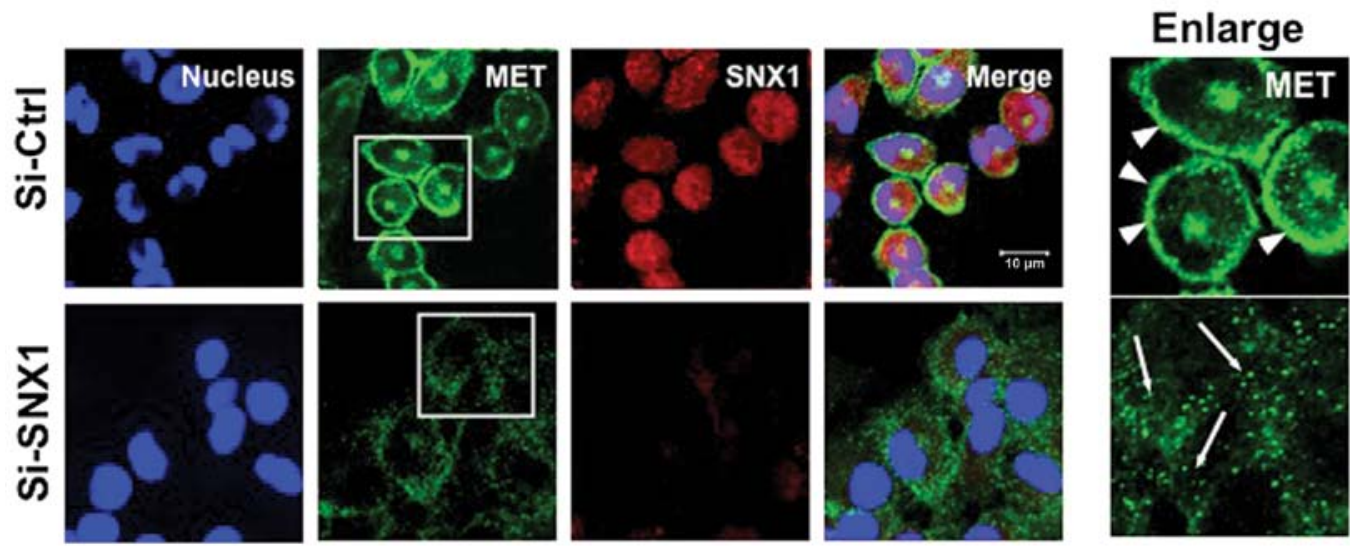

B
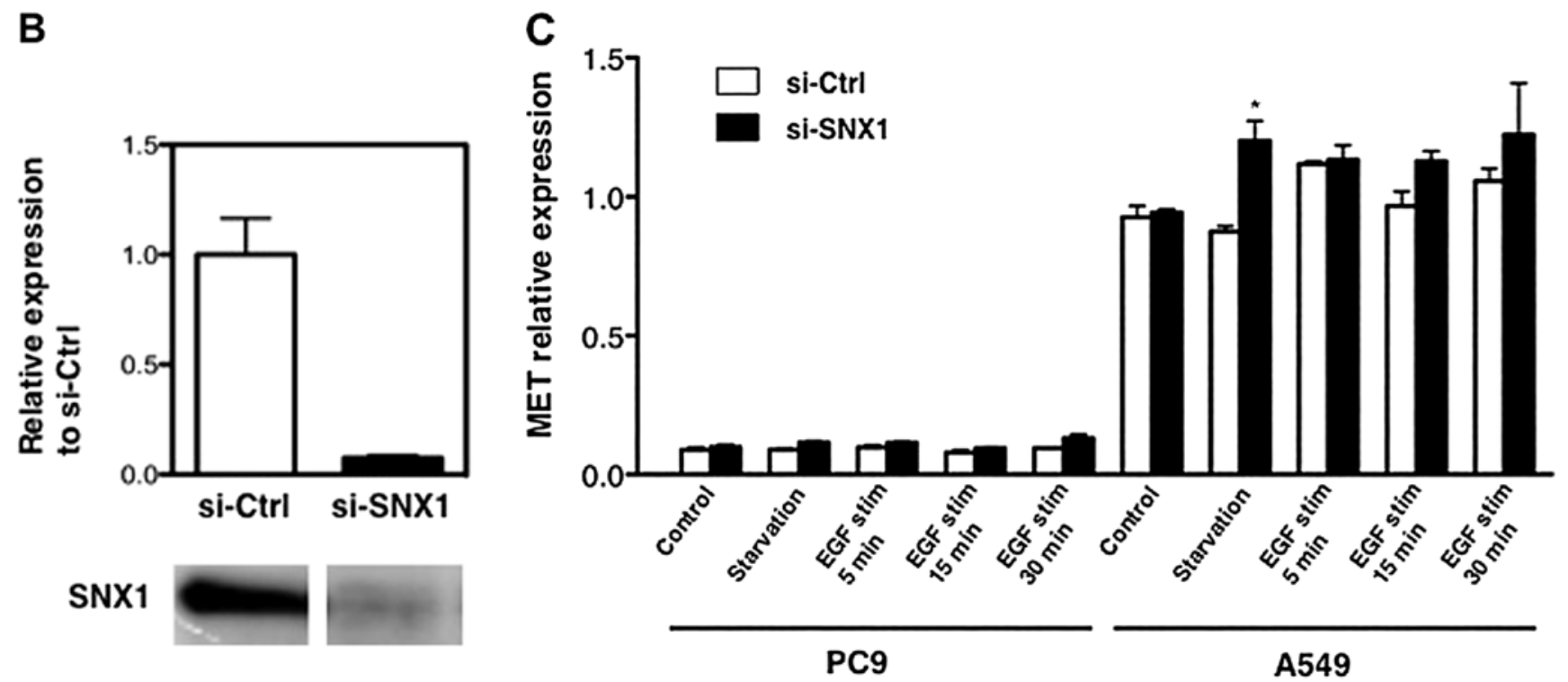

Figure 2. Depletion of SNX1 by sequence specific siRNA causes a dramatic alteration in the intracellular distribution of MET in the gefitinib-resistant A549 cells. The A549 cells transfected with siRNA-control (si-Ctrl) or siRNA-SNX1 (si-SNX1) were fixed and double-stained for MET (green) and SNX1 (red) in (A) as described in Materials and methods. Each cell line was stained with DAPI (blue) to reveal the nuclei. Bar, $10 \mu \mathrm{m}$. Lower column shows the merged images of MET staining in the A549 cells transfected with si-Ctrl or si-SNX1, and white squares indicate enlarged regions. The white arrowheads indicate the MET-positive staining localized in the plasma membranes of A549 cells, and the long white arrows indicate the MET staining dispersed throughout the cytoplasm of the cells transfected with si-SNX1. Also the amounts of SNX1 in the A549 cells transfected with si-Ctrl or si-SNX1 were detected by the western blot analysis as shown in (B), and the density of each band was quantified using NIH Image software as described in Materials and methods. Note that the trasfection of si-SNX1 into the A549 cells caused a complete depletion of SNX1. (C) qRT-PCR analysis of MET mRNA in NSCLC PC9 and A549 cells transfected with si-Ctrl or si-SNX1. The NSCLC PC9 and A549 cells transfected with si-Ctrl or si-SNX1 were stimulated at $37^{\circ} \mathrm{C}$ with EGF $(100 \mathrm{ng} /$ $\mathrm{ml}$ ) for the indicated times, and then analyzed for the expression of MET mRNA by qRT-PCR analysis as described in Materials and methods. Expression levels of MET mRNA were normalized with that of $\beta$-actin. The error bar denotes SD from three separate experiments, and significance was determined using Student's t-test. Asterisk indicates significant difference between the values ( $\mathrm{p}<0.05)$.

plasma membranes and that EGFR-positive staining was not co-localized with transferrin-positive early endosomes in A549 cells.

Knockdown of SNX1 by specific siRNA effectively downregulates the expression of endogenous SNX1 protein levels and causes a dramatic alteration in the intracellular distribution of plasma membrane-associated MET in the gefitinib-resistant NSCLC cell line. To examine the biological function of SNX1 in regulating HGF-stimulated MET signaling and its endocytosis, we used siRNA to knockdown the endogenous of SNX1 in the NSCLC cell line A549. First, we examined the depletion of endogenous SNX1 protein levels by confocal immunofluorescence microscopy. The results showed that the endogenous SNX1 was successfully depleted using siRNA in A549 cells (Fig. 2A). Second, western blot analysis (Fig. 2B) revealed that endogenous MET expression was almost completely silenced by specific siRNA in the gefitinib-resistant cell line A549. Third, to examine the endogenous MET mRNA transcript levels, the gefitinib-sensitive NSCLC cell line PC9 and gefitinib-resistant NSCLC cell line A549 were transfected with siRNA-control or siRNA-SNX1 and then used in qRT-PCR analysis. The results shown in Fig. 2C, indicate that siRNA-SNX1 suppressed SNX1 mRNA in both NSCLC 
cell lines. Moreover, it should be noted that SNX1 knockdown did not change the endogenous expression of MET transcript in the NSCLC cell lines (Fig. 2C). It was interesting to find that the endogenous expression of MET mRNA transcripts was apparently higher in the gefitinib-resistant cell line A549 compared to that of the gefitinib-sensitive cell line PC9; the expression level of MET transcripts in the gefitinib-resistant cell line A549 was approximately 6.2-fold greater than that in the gefitinib-sensitive cell line PC9 (Fig. 2C).

To investigate the alteration in the intracellular distribution of MET in the gefitinib-resistant cell line A549, the cells transfected with the siRNA-control or the siRNA-SNX1 were double-labeled with either antibodies specific to MET or antibodies specific to SNX1. The confocal immunofluorescence microscopy studies showed that in A549 cells transfected with siRNA-contol, MET was mostly seen to be associated with plasma membranes, and MET-positive staining was not co-localized with SNX1-positive early endosomes (Fig. 2A). This immunostaining pattern of MET in A549 cells was similar to that in PC9 cells (data not shown). In contrast, in A549 cells transfected with siRNA-SNX1, large amounts of plasma-membrane-associated MET staining were not seen, and there was increased small punctate stainings of MET distributed throughout the cytoplasm. These results suggest that depletion of SNX1 dramatically alters the distribution of plasma membrane-associated MET in A549 cells.

We further analyzed a change in the intracellular distribution of MET in the siRNA-SNX1-transfected cells. Cells in the siRNA-control or the siRNA-SNX1-transfected groups were fixed and double-labeled with antibodies to MET and LAMP1 or stained with MET antibody and the endocytosed Texas red-labeled transferrin, and the change in the intracellular distribution of MET was examined by confocal immunofluorescence microscopy. The results showed that considerable amounts of plasma membrane-associated MET, as observed in the siRNA-control transfected cells, were absent from the cells and large amounts of MET-positive small punctate vesicles were seen to be dispersed throughout the cytoplasm, in which some MET-positive staining obviously overlapped with the endocytosed transferrin-positive vesicles (Fig. 3B). Co-localization of MET- and LAMP1-positive staining was not discernible since most MET-positive staining was absent in the cells (Fig. 3A). We also examined the effect of siRNA-SNX1 transfection into A549 cells on the cellular distribution of EGFR. Cells in the siRNA-control or the siRNA-SNX1-transfected groups were fixed and double-labeled with EGFR antibody and the endocytosed Texas red-labeled transferrin. The results indicated that most of the plasma-membrane associated EGFR seen in the siRNA-control-transfected cells was not present, and that increased amounts of EGFR-positive punctate small vesicles were co-localized with the endocytosed Texas red-labeled transferrin that were seen to be spreading throughout the cytoplasm (Fig. 3C). These observations were consistent with those seen in the case of MET, indicating that the transfection of siRNA-SNX1 in A549 cells can cause a dramatic change in the plasma membrane-distribution of MET, leading to increasing amounts of MET- or EGFR-positive small vesicles in the cytoplasm, and the disappearance of these labels from the plasma membranes. Quantitative analysis of the co-localization rate was calculated as the percentage of the integrated density of the endocytosed Texas red-labeled transferrin-early endosome marker-co-localizing MET or EGFR compared with that of total MET or EGFR (\% total MET or EGFR) in A549 cells transfected with siRNA-control or siRNA-SNX1 (Fig. 3D). Our data verified that transferrin-colocalizing MET (20.2 vs. $2.4 \%$ total MET) or EGFR (24.1 vs. 3.3\% total EGFR) is markedly higher in the siRNA-SNX-transfected cells than in the siRNA-control-transfected cells (Fig. 3D). These results indicate that membrane trafficking of MET or EGFR between plasma membranes and early endosomes may be considerably suppressed in A549 cells.

Depletion of SNX1 stimulates efficient endocytosis of HGF-induced MET and phosphorylation of MET via the early/late endocytic pathway in a gefitinib-resistant NSCLC cell line. We recently reported the novel evidence that gefitinib-resistant cells show internalized EGFR accumulation in aggregated early endosomes, and that this is associated with SNX1 (26-28). In contrast, gefitinib-sensitive cells show efficient endocytosis of EGFR. We therefore imply that impairment of protein function, such as SNX1 in the regulation of EGFR trafficking in the early endocytic pathway, might cause these perturbations in EGFR endocytosis, leading to gefitinib resistance in NSCLC cell lines.

Accordingly, we next examined the effect of SNX1 silencing on HGF-induced MET endocytosis via the early/late endocytic pathway in A549 cells. The cells transfected with siRNA-control or siRNA-SNX1 were stimulated at $37^{\circ} \mathrm{C}$ with HGF for 5, 15 or $30 \mathrm{~min}$, and then double-stained for the internalized HGF (stained by anti-HGF $\alpha$-chain antibody) and cathepsin D (stained by anti-cathepsin D antibody), a marker of lysosomes, or the internalized HGF and the endocytosed Texas red-labeled transferrin. Confocal immunofluorescence studies demonstrated a rapid endocytosis of HGF, and that the distribution of small punctate vesicles that stained positive for internalized HGF overlapped with the Texas red-labeled transferrin was seen in the cytoplasm of the cells transfected with siRNA-SNX1 after 5-min incubation (Fig. 4B). In addition, co-localization of the internalized HGF and cathepsin D-positive lysosomes was observed in the perinuclear region after the 15-min incubation (Fig. 4A). Furthermore, an increased amount of internalized HGF co-localized with the cathepsin D-positive lysosomes was seen after $30 \mathrm{~min}$. In contrast, in the cells transfected with siRNA-control, the internalization of HGF was considerably suppressed and the endocytosed HGF-positive staining was not co-localized with cathepsin D-positive vesicular structures even after 30 min internalization (Fig. 4A). Double staining of HGF and cathepsin D showed that HGF was rapidly internalized and transported to lysosomes after 15 min of HGF stimulation with HGF in the cells transfected with siRNA-SNX1, but endocytosis of HGF was considerably suppressed and the internalized HGF remained co-localized with early endosomes after $30 \mathrm{~min}$ of HGF stimulation in the cells transfected with siRNA-control. The co-localization rate was calculated as the percentage of the integrated density of early endosome or lysosome marker co-localizing HGF compared with that of total HGF (\% total HGF) (Fig. 4C and D). The co-localization rate calculations confirmed that cathepsin D-co-localizing HGF was greater in the siRNA-SNX1-transfected cells than 
A MET/LAMPI
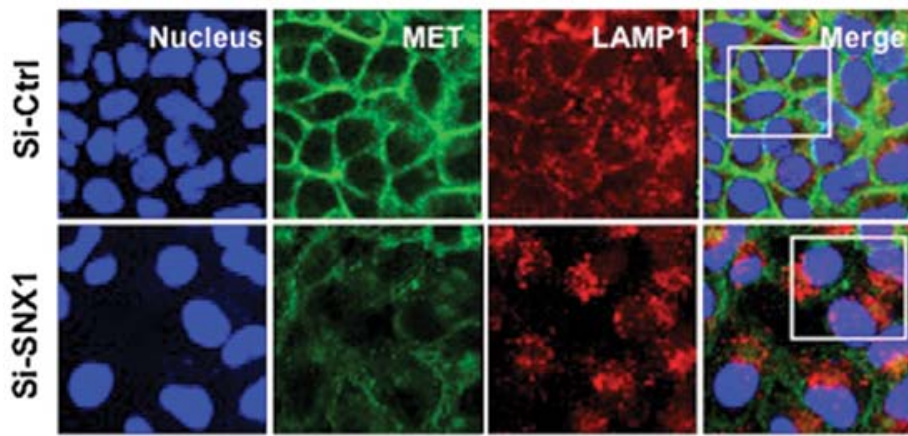

\section{Enlarge}
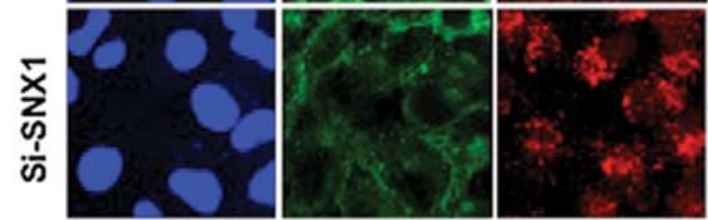

B MET/Tf
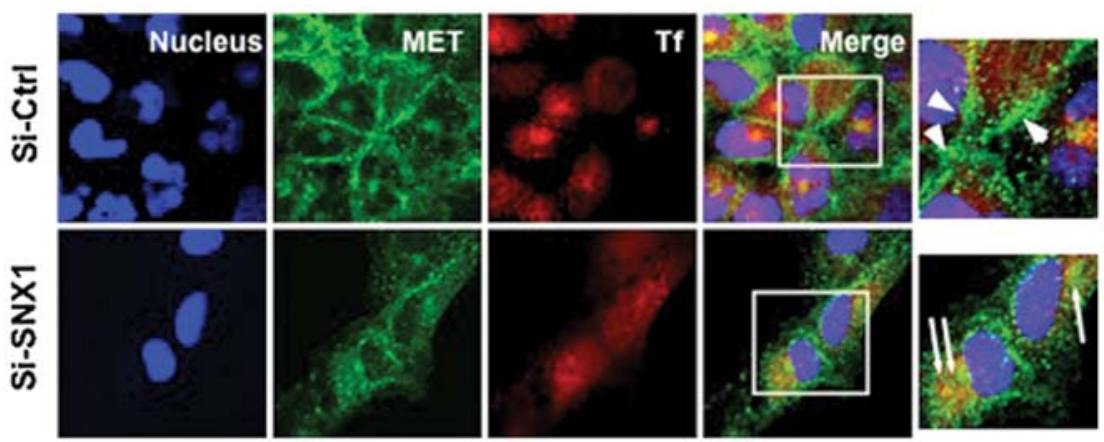

\section{EGFR/Tf}
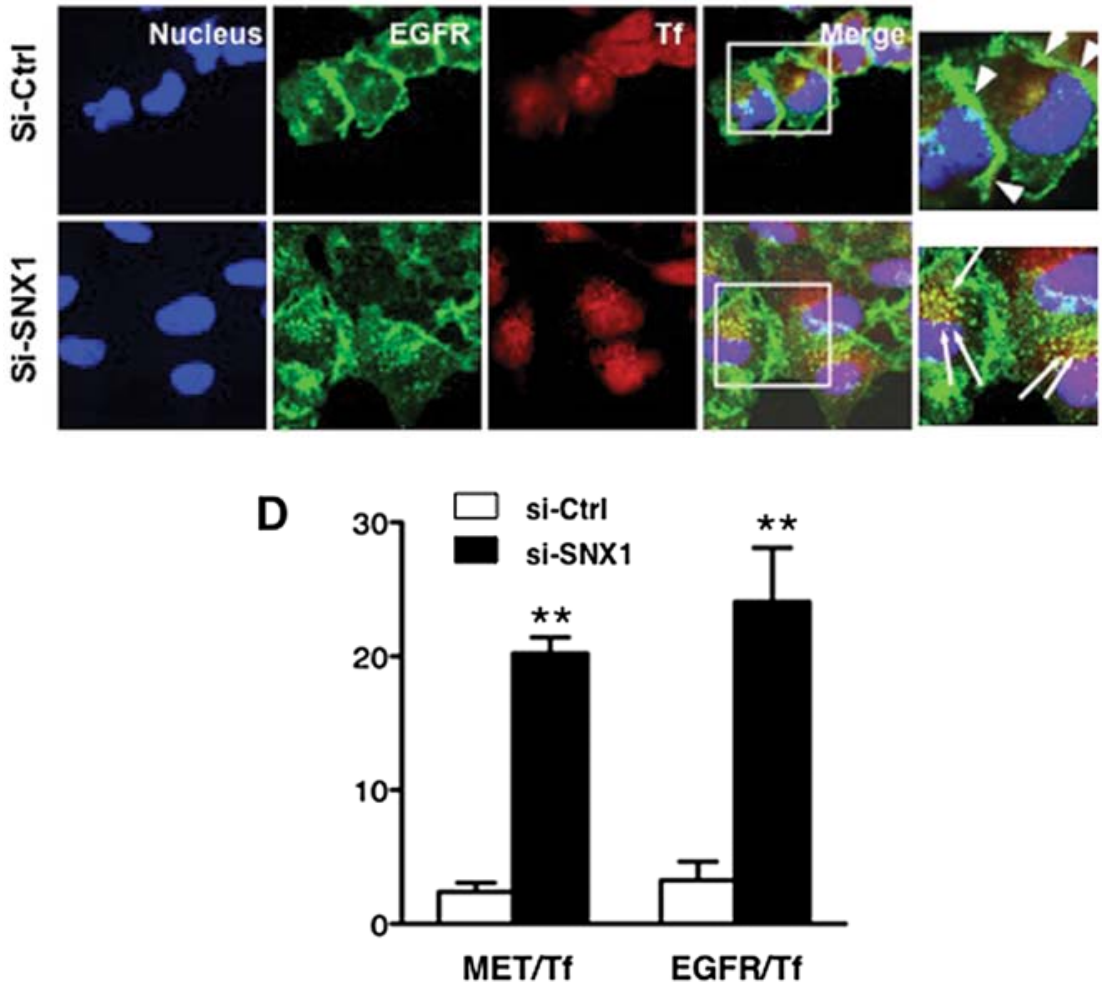

Figure 3. Expression of siRNA-SNX1 in the gefitinib-resistant cell line A549 causes redistribution of MET from plasma membranes to early endosomes. The A549 cells transfected with siRNA-control (si-Ctrl) or siRNA-SNX1 (si-SNX1) were incubated with Texas red-transferrin (red) and fixed as described in Materials and methods. Then the cells were double-stained for (A) MET (green) and LAMP1 (red); (B) MET (green) and the endocytosed Texas redlabeled transferrin (red); or (C) EGFR (green) and the endocytosed Texas red-transferrin (red). Each cell line was stained with DAPI (blue) to reveal the nuclei. Right column shows the merged images of MET or EGFR staining in the A549 cells transfected with si-Ctrl or si-SNX1, and white squares indicate enlarged regions. The white arrowheads indicate the MET- or EGFR-positive staining distributed in the plasma membranes of A549 cells, and the long white arrows indicate the merged confocal images as yellow of MET or EGFR and the endocytosed transferrin-staining dispersed throughout the cytoplasm of the si-SNX1 transfected cells. (D) Left panel, quantitative analysis was carried out to determine the colocalization rate between MET and the endocytosed transferrin in the si-Ctrl-transfected cells (white column) or the si-SNX1-transfected cells (black column). Right panel, the colocalization rate between EGFR and the endocytosed Texas red-labeled transferrin in the si-Ctrl-transfected cells (white column) or the si-SNX1-transfected cells (black column). Values are the percentage of the integrated density of transferrin-colocalizing MET or EGFR compared to that of total MET or EGFR. The error bar denotes $\mathrm{SD}$ from three separate experiments, and the asterisks indicate significant difference between the values $\left({ }^{* *} \mathrm{p}<0.01 ; \mathrm{n}=10\right.$ fields $)$. 
A

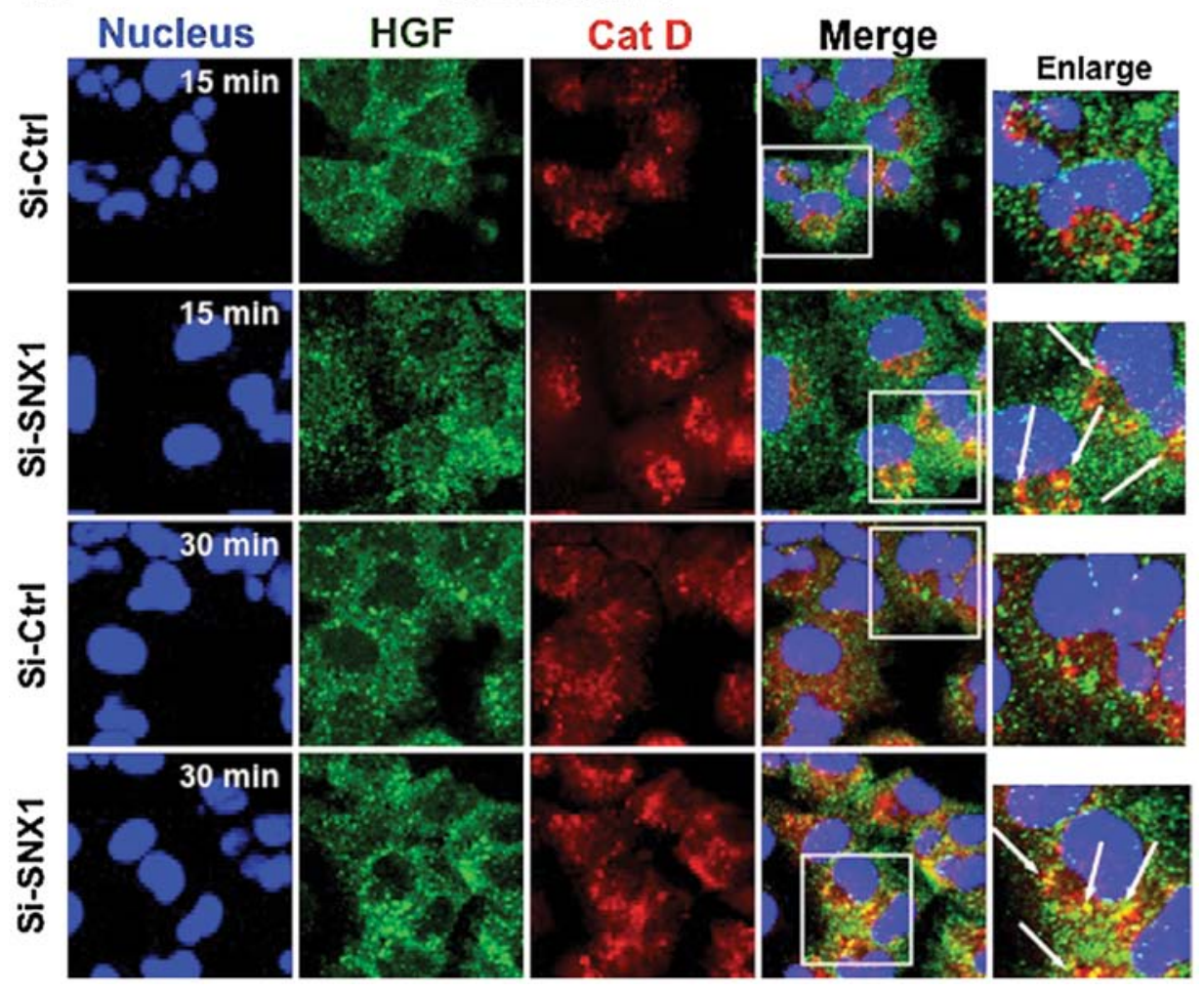

B

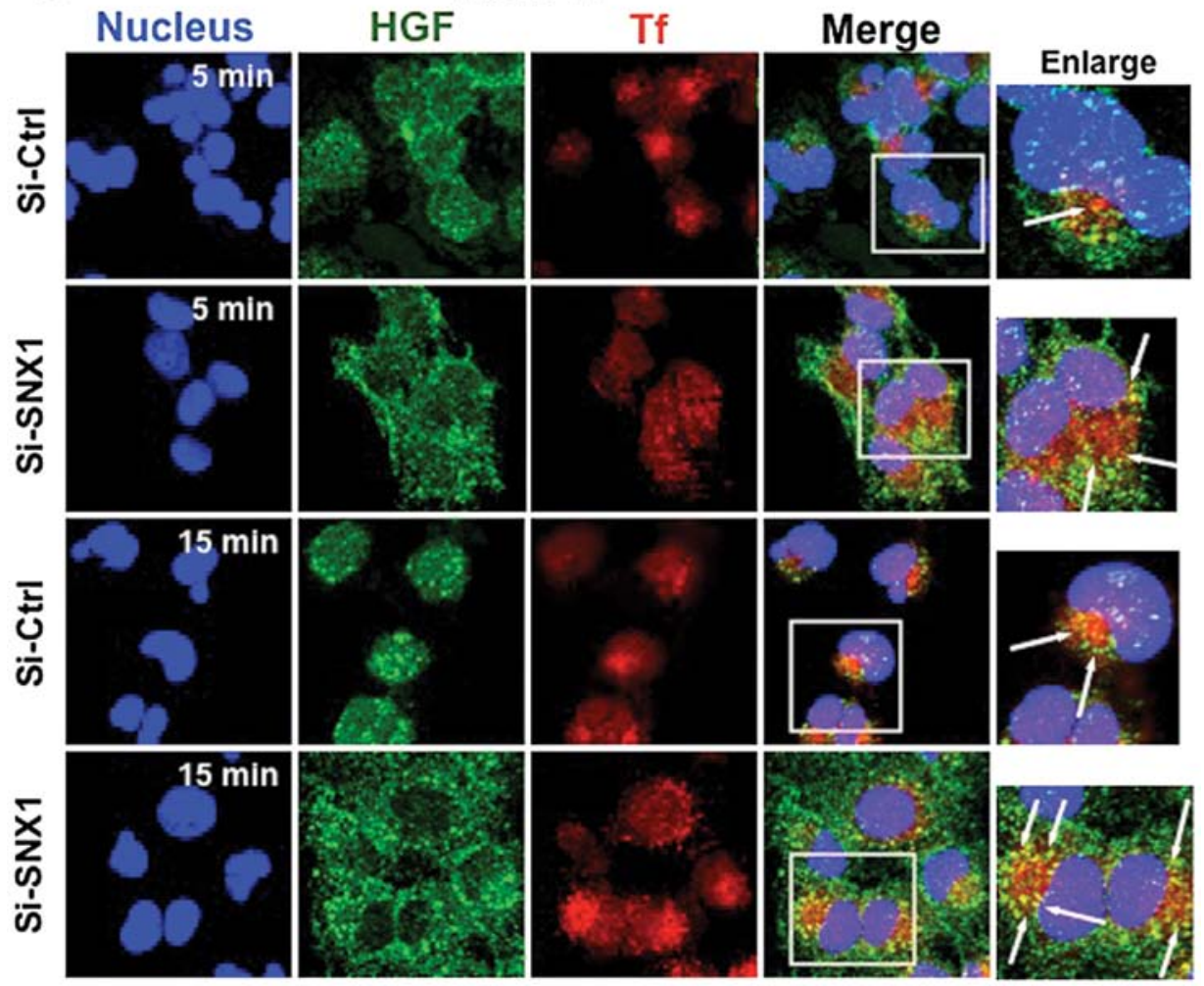

Figure 4. Silencing of SNX1 by siRNA enhances HGF-induced MET endocytosis in the gefitinib-resistant NSCLC cell line. The A549 cells transfected with siRNA-control (si-Ctrl) or siRNA-SNX1 (si-SNX1) were pretreated at $37^{\circ} \mathrm{C}$ for $30 \mathrm{~min}$ in the presence of Texas red-transferrin in prewarmed medium. The cells were then incubated with $\mathrm{HGF}(100 \mathrm{ng} / \mathrm{ml})$ at $37^{\circ} \mathrm{C}$ for 5,15 or $30 \mathrm{~min}$, and the distribution of internalized HGF stained with anti-HGF $\alpha$-chain antibody and lysosomes stained with anti-cathepsin $\mathrm{D}$ antibody was then assessed by confocal immunofluorescence microscopy after fixation of the cells as described in Materials and methods. Superimposed images of the internalized HGF (green) with cathepsin D (red) and the internalized HGF (green) with the endocytosed Texas red-labeled transferrin (red) are shown in (A) and (B), respectively. Each cell line was stained with DAPI (blue) to reveal the nuclei. Right column shows the merged images of HGF and cathepsin D staining in (A) or HGF and Texas red-transferrin staining in (B) in the A549 cells transfected with si-Ctrl or si-SNX1, and white squares indicate enlarged regions. The long white arrows indicate the merged confocal images as yellow of HGF- and cathepsin D-positive staining or HGF- and the endocytosed transferrin-staining in the cells. 


\section{HGF/Cathepsin D}

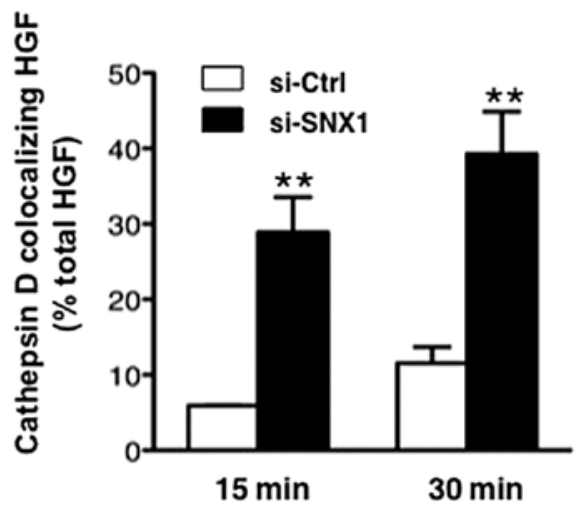

D HGF/Tf

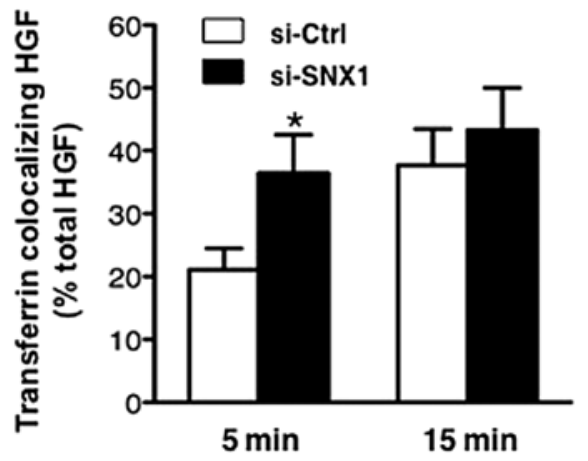

Figure 4. Continued. The colocalization rate between the internalized HGF and cathepsin D in the A549 cells transfected with si-Ctrl (white columns) or si-SNX1 (black columns) after 15 or 30 min of HGF stimulation is shown in (C), and the colocalization rate between the internalized HGF and Texas red-labeled transferrin in the A549 cells transfected with si-Ctrl (white columns) or si-SNX1 (black columns) after 5 or 15 min of HGF stimulation is shown in (D). Values are the percentage of the integrated density of cathepsin D or Texas red-labeled transferrin-colocalizing HGF compared to that of total HGF. The error bar denotes SD from three separate experiments, and significance was determined using Student's t-test. Asterisks indicate significant difference between the values $\left({ }^{*} \mathrm{p}<0.05 ;{ }^{* *} \mathrm{p}<0.01\right)$

in the siRNA-control-transfected cells after both $15 \mathrm{~min}$ $(28.9 \pm 4.6$ vs. $5.9 \pm 0.1 \%$ total $\mathrm{HGF})$ and $30 \mathrm{~min}(39.3 \pm 5.6$ vs. $11.6 \pm 2.1 \%$ total HGF) of HGF stimulation (Fig. 4C). However, the amounts of transferrin-co-localizing HGF appeared to be similar in the cells transfected with siRNA-SNX1 and in the cells transfected with siRNA-control after $15 \mathrm{~min}(43.3 \pm 6.7$ vs. $36.5 \pm 6.1 \%$ total HGF) of HGF stimulation (Fig. 4D). These results demonstrated that the endocytosed HGF was retained in early endosomes before being sorted to late endosomes/lysosomes in the cells transfected with siRNA-control, whereas it was quickly sorted to late endosomes/lysosomes in the cells transfected with siRNA-SNX1.

To further substantiate the effect of SNX1 depletion on the HGF-induced phosphorylation of MET and the endocytosis of pMET, A549 cells transfected with siRNA-control or siRNA-SNX1 were stimulated with HGF for 15 or $30 \mathrm{~min}$, and then double-stained for pMET and LAMP1, or for pMET and the endocytosed Texas red-labeled transferrin. Confocal immunofluorescence microscopy studies revealed that in the cells transfected with siRNA-SNX1, a significant increase in co-localized pMET and LAMP1 was seen after 15 or 30 min of HGF stimulation. In contrast, pMET was predominantly colocalized with the transferrin-positive early endosomes, and no co-localization of pMET was seen with LAMP1-positive vesicles in the siRNA-control-transfected cells (Fig. 5A). An increase of co-localized pMET and transferrin was also observed both in the siRNA-control- and siRNA-SNX1-transfected cells after 30 min of HGF stimulation (Fig. 5B). The co-localization rate calculations confirmed that LAMP1-co-localizing pMET was greater in the cells transfected with siRNA-SNX1 than in the cells transfected with siRNA-control after both $15 \mathrm{~min}(17.2 \pm 6.1$ vs. $7.7 \pm 0.9 \%$ total pMET) and $30 \mathrm{~min}(26.1 \pm 3.4$ vs. $6.7 \pm 0.2 \%$ total pMET) of HGF stimulation (Fig. 5C), whereas the amounts of transferrin-co-localizing pMET appeared to be similar in the cells transfected with siRNA-SNX1 to that in the cells transfected with siRNA-control after both $15 \min (37.0 \pm 3.4$ vs. $33.7 \pm 5.9 \%$ total pMET) and 30 min $(36.5 \pm 3.8$ vs. $37.7 \pm 4.1 \%$ total pMET $)$ of HGF stimulation (Fig. 5D). These data demonstrated that depletion of SNX1 by siRNA rescues the rapid endocytosis and endocytic trafficking of MET/pMET via the early/late endocytic pathway in gefitinib-resistant cells. In contrast, an aberration of MET endocytosis was noted from the early to late endocytic pathway in the gefitinib-resistant cells transfected with siRNA-control.

We investigated the effects of bafilomycin A1, a lysosome inhibitor, on the HGF-induced endocytosis of pMET in the A549 cells transfected with siRNA-control or siRNA-SNX1. Cells were stimulated with HGF for 30 or $60 \mathrm{~min}$ in the presence of bafilomycin A1 and then double-stained for pMET and LAMP1, or for pMET and the endocytosed Texas redlabeled transferrin. The results showed that the amount of pMET staining co-localized with LAMP1 increased after 30 or $60 \mathrm{~min}$ of HGF stimulation (Fig. 6A), and an increase of co-localized pMET and transferrin staining was also observed both in the siRNA-control and siRNA-SNX1 transfected cells after 30 min of HGF stimulation (Fig. 6B). The co-localization rate calculations demonstrated that in the presence of bafilomycin A1,LAMP1-co-localizing pMET was greater in the cells transfected with siRNA-SNX1 than in the cells transfected with siRNA-control after both $30 \mathrm{~min}(29.7 \pm 3.6$ vs. $11.7 \pm 4.0 \%$ total pMET) and $60 \mathrm{~min}(38.2 \pm 8.9$ vs. $17.7 \pm 4.6 \%$ total pMET) of HGF stimulation. An increased amount of transferrinco-localizing pMET was seen in the cells transfected with siRNA-SNX1 and in the cells transfected with siRNA-control after $30 \mathrm{~min}(25.0 \pm 3.6$ vs. $16.1 \pm 0.7 \%$ total pMET) (Fig. 6C) and $60 \mathrm{~min}(27.1 \pm 5.3$ vs. $17.7 \pm 7.4 \%$ total pMET) of HGF stimulation (Fig. 6D). These results indicate that bafilomycin A1 treatment significantly blocked HGF-induced pMET endocytosis, and increased amounts of pMET staining colocalized with LAMP1-positive late endosomes/lysosomes. Therefore, bafilomycin A1 has a stronger effect on the HGF-induced pMET endocytosis in the cells transfected with siRNA-SNX1 than that in cells transfected with the siRNA-control. 
A

PMET/LAMPI
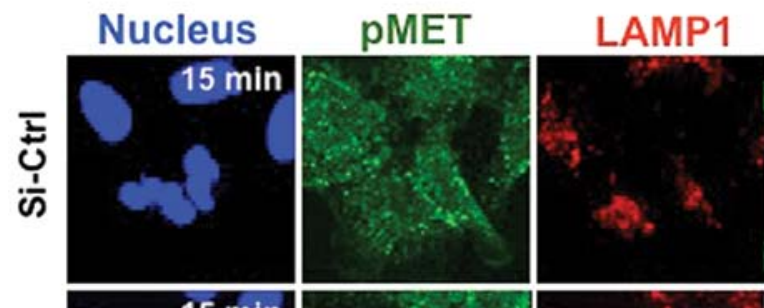

\section{Merge}
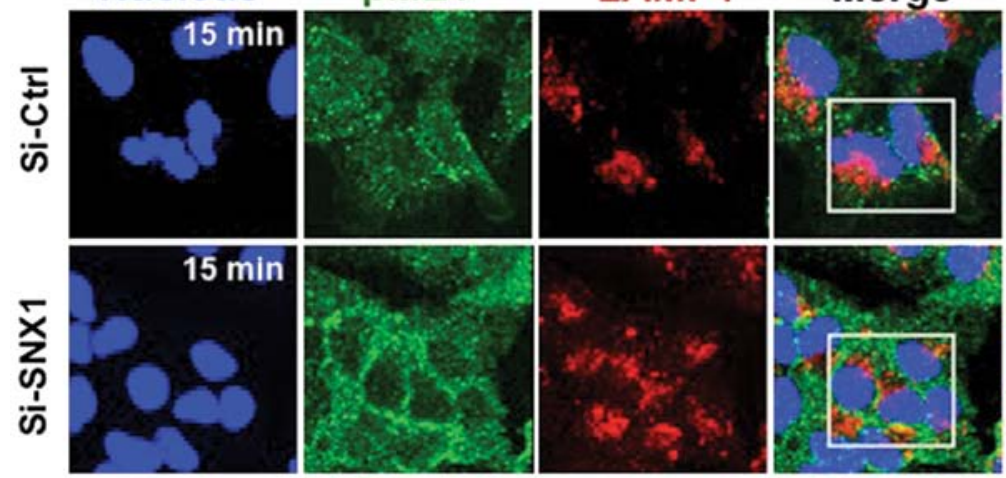

\section{Enlarge}
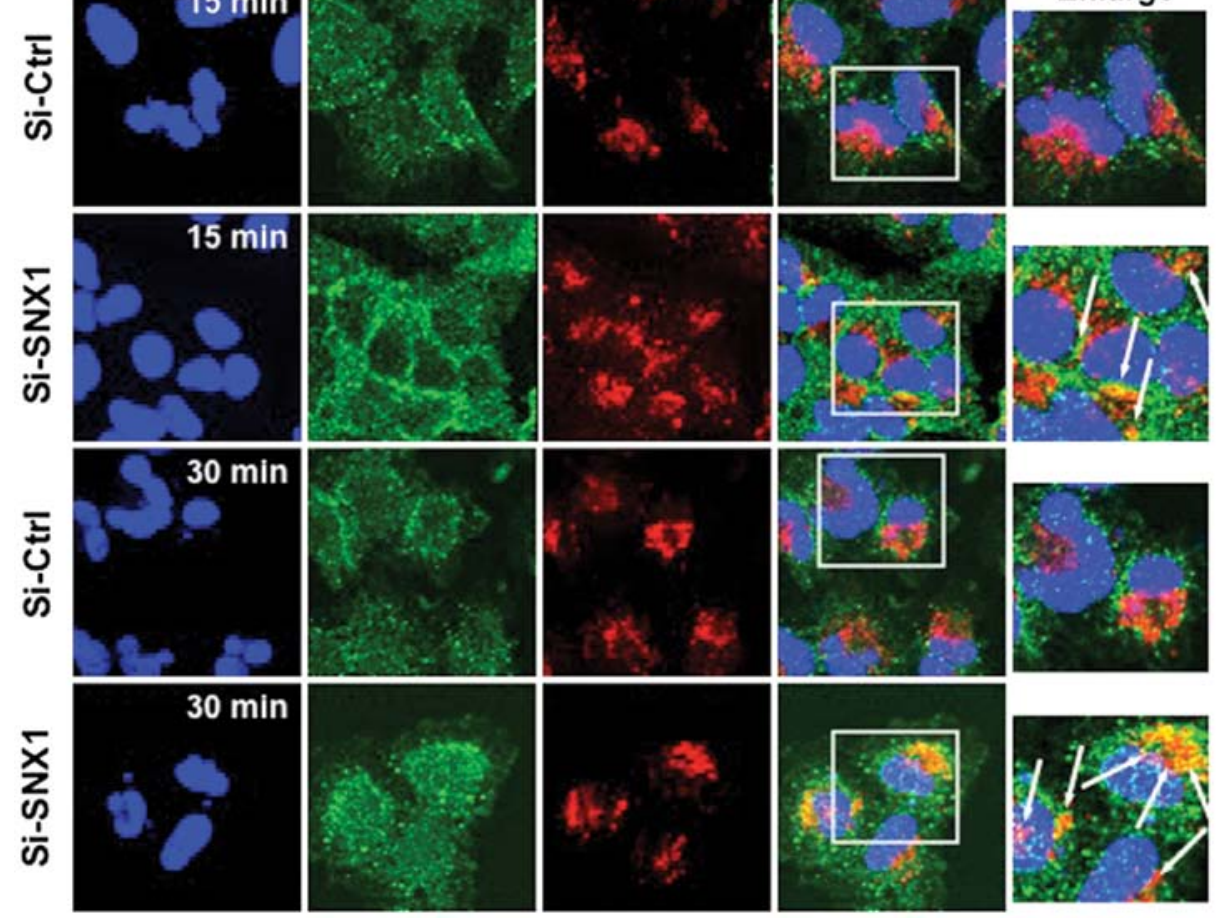

B

\section{pMET/Tf}
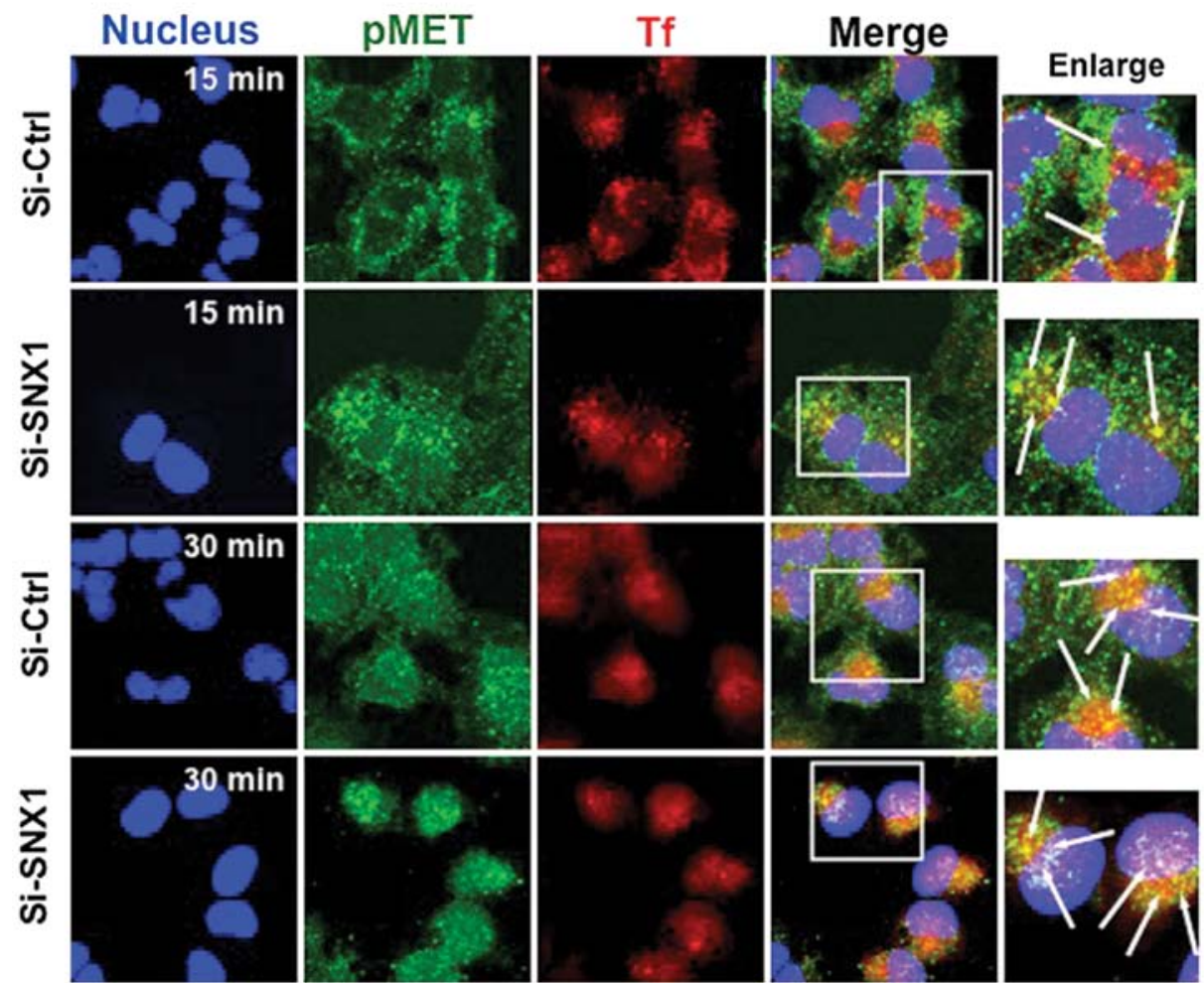

Figure 5. Evidence that depletion of SNX1 promotes HGF-induced phosphorylated MET endocytosis in the gefitinib-resistant human lung cancer cell line. The A549 cells transfected with siRNA-control (si-Ctrl) or siRNA-SNX1 (si-SNX1) were pretreated at $37^{\circ} \mathrm{C}$ for 30 min in the presence of Texas redtransferrin in prewarmed medium, and the cells were then incubated with $\mathrm{HGF}(100 \mathrm{ng} / \mathrm{ml})$ at $37^{\circ} \mathrm{C}$ for $15 \mathrm{or} 30 \mathrm{~min}$, and the distribution of internalized phosphorylated MET (pMET) stained with anti-pMET antibody and late endosomes/lysosomes stained with anti-LAMP1 antibody was then assessed by confocal immunofluorescence microscopy after fixation of the cells as described in Materials and methods. Superimposed images of pMET (green) with LAMP1 (red) and pMET (green) with the endocytosed Texas red-labeled transferrin (red) are shown in (A) and (B), respectively. Each cell line was stained with DAPI (blue) to reveal the nuclei. Right column shows the merged images of pMET and LAMP1 staining in (A) or pMET and Texas red-transferrin staining in (B) in the A549 cells transfected with si-Ctrl or si-SNX1, and white squares indicate enlarged regions. The long white arrows indicate the merged confocal images as yellow of pMET- and LAMP1-positive staining or pMET- and the endocytosed transferrin-staining in the cells. 


\section{PMET/LAMP1}

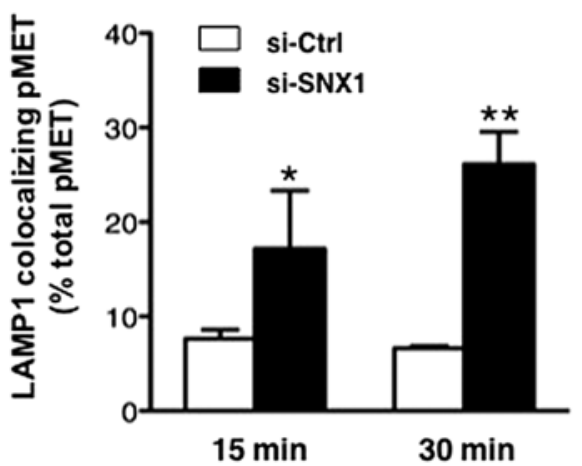

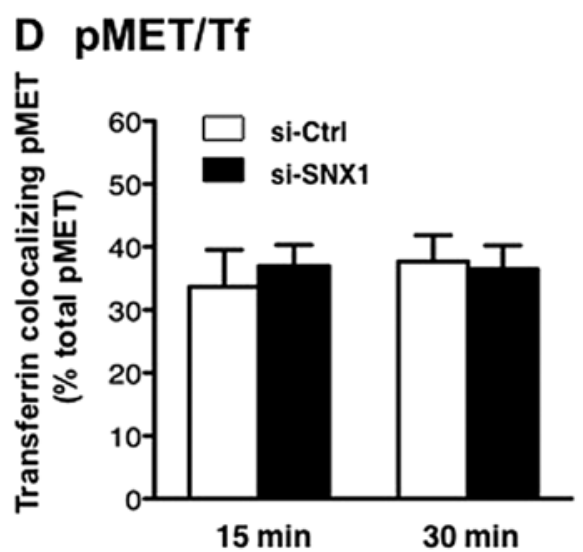

Figure 5. Continued. The colocalization rate between pMET and LAMP1 in the A549 cells transfected with si-Ctrl (white columns) or si-SNX1 (black columns) after 15 or $30 \mathrm{~min}$ of HGF stimulation is shown in (C), and the colocalization rate between the pMET and Texas red-labeled transferrin in the A549 cells transfected with si-Ctrl (white columns) or si-SNX1 (black columns) after 15 or 30 min of HGF stimulation is shown in (D). Values are the percentage of the integrated density of LAMP1 or Texas red-labeled transferrin-colocalizing pMET compared to that of total pMET. The error bar denotes SD from three separate experiments, and significance was determined using Student's t-test. Asterisks indicate significant difference between the values $\left({ }^{*} \mathrm{p}<0.05\right.$; $\left.{ }^{* *} \mathrm{p}<0.01\right)$.

Depletion of SNX1 stimulates the HGF-induced phosphorylation of MET and phosphorylated MET degradation in the gefitinib-resistant NSCLC cell line. To analyze the effect of the silencing of SNX1 protein levels on the HGF-induced increase of pMET in the gefitinib-resistant A549 cells, cells transfected with siRNA-control or siRNA-SNX1 were stimulated with $\mathrm{HGF}$ at $37^{\circ} \mathrm{C}$ for the indicated times, and then the cell lysates were analyzed by western blotting. As shown in Fig. 7A and D, the treatment of the cells with siRNA-SNX1 completely suppressed the endogenous expression of SNX1 protein in the A549 cells.

Furthermore, we found novel evidence that the expression level of pMET was considerably increased at $60 \mathrm{~min}$ after HGF-stimulation in the siRNA-SNX1-transfected A549 cells compared to the increase seen in the siRNA-control-transfected cells (Fig. 7A). Quantitative analysis showed that in the siRNA-SNX1-transfected A549 cells, the induced expression level of pMET protein following HGF stimulation was about 118-fold and 39.9-fold at 60 and $120 \mathrm{~min}$, respectively (Fig. 7B). In contrast, in the siRNA-control-transfected A549 cells, the increase of the pMET expression was 63.5-fold and 40.9-fold at 60 and $120 \mathrm{~min}$, respectively. It should be also noted that the expression levels of pMET in the siRNA-SNX1-transfected cells was 1.7-fold (at $60 \mathrm{~min}$ ) higher than that in the siRNA-controltransfected cells after HGF stimulation (Fig. 7B) and that an increase in phosphorylated EGFR (pEGFR) was not observed in the cells stimulated with HGF (Fig. 7C), thereby demonstrating that HGF treatment selectively stimulates phosphorylation of MET within 60 min in A549 cells.

The increased pMET appeared to be rapidly degraded within $4 \mathrm{~h}$ in the siRNA-SNX1-transfected cells (Fig. 7A and B), indicating that intracellular degradation of HGF-induced pMET proceeds efficiently via an endosomal/lysosomal pathway in A549 cells, since large amounts of accumulated pMET were observed in the cells when the cells were treated with HGF in the presence of bafilomycin A1. These results indicate that depletion of SNX1 by siRNA efficiently increases endogenous phosphorylation of MET and its degradation via the endocytic pathway, thereby implying that SNX1 plays a suppressive role in the phosphorylation and downregulation of MET via the endocytic pathway in the gefitinib-resistant NSCLC cell line A549.

\section{Discussion}

In the present study, we investigated the intracellular regulatory function of SNX1 with regard to HGF-induced endocytosis and downregulation of MET/pMET by using RNAi-mediated knockdown approaches via the early/late endocytic pathway in gefitinib-resistant NSCLC cell line A549. Using confocal immunofluorescence microscopy and qRT-PCR techniques, we verified a significant reduction of endogenous SNX1 protein expression and mRNA expression in the gefitinib-sensitive cell line PC9 and the gefitinib-resistant cell line A549 transfected with siRNA-SNX1. We also found that endogenous expression of MET transcripts in the gefitinib-resistant cell line A549 was significantly higher than in the gefitinib-sensitive cell line PC9; the expression level of MET transcript in A549 cells was approximately 6.2-fold that of the values in PC9 cells, and knockdown of SNX1 in these NSCLC cell lines did not change the expression of MET transcript. Therefore, we suggest that the expression of SNX1 protein might not have any effect on the regulation of MET mRNA expression in these NSCLC cell lines.

We provided novel evidence by using confocal immunofluorescence microscopy that depletion of endogenous SNX1 by siRNA-SNX1 induced efficient endocytosis of ligand-induced MET or pMET via the early/late endocytic pathway in the gefitinib-resistant NSCLC cell line A549. We showed that increased co-localization of the internalized HGF complexed with MET and cathepsin D or of pMET and LIMPII after 15 min internalization in the gefitinib-resistant cells transfected with siRNA-SNX1. In contrast, in the siRNA-control-transfected cells, the internalization of HGF was suppressed and the endocytosed HGF-positive staining and pMET staining did not overlap with cathepsin D-positive lysosomal vesicular structures and LAMP1-positive late endosome vesicles, respectively, even after $30 \mathrm{~min}$ of HGF stimulation. Our data suggest that depletion of SNX1 stimulates HGF-induced MET/pMET 
A

pMET/LAMP1
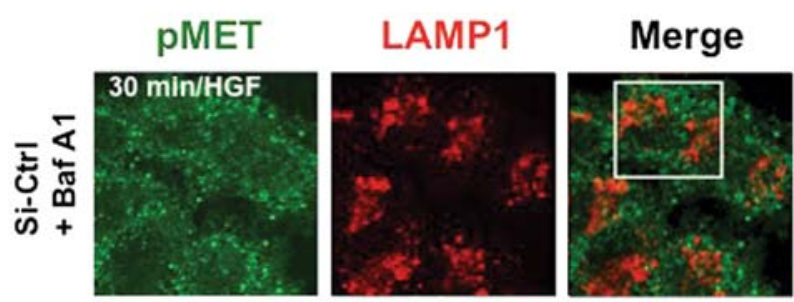

Enlarge
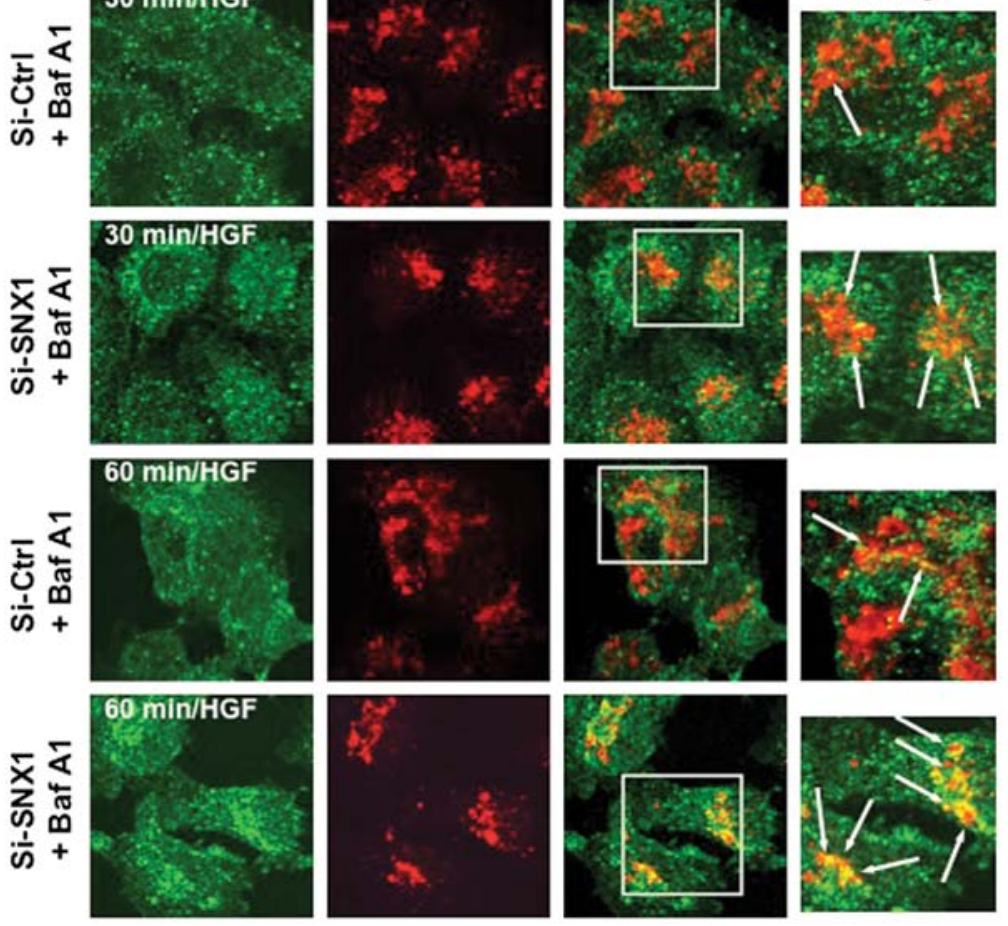

B
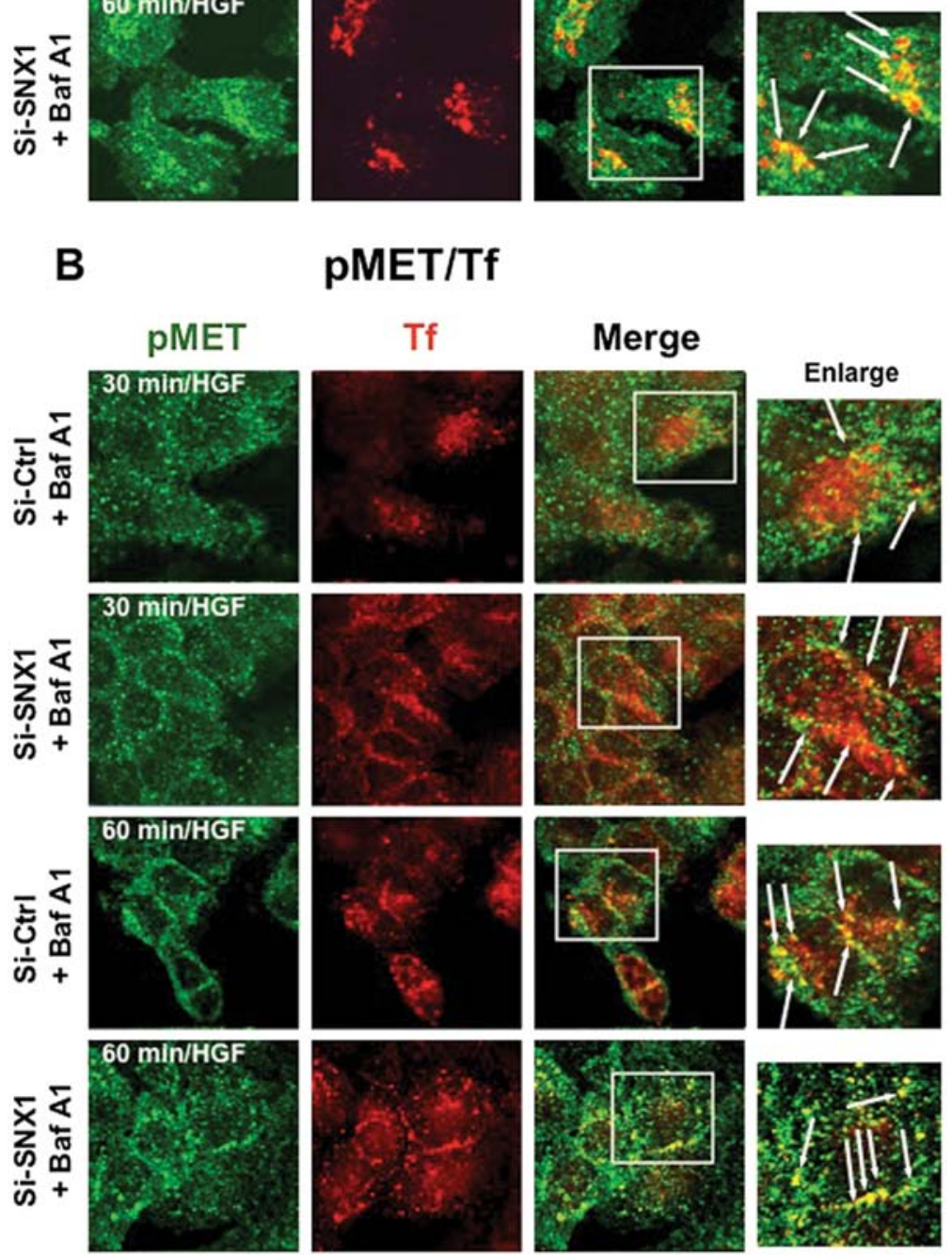

Figure 6. Bafilomycin A1 suppresses efficiently HGF-induced phosphorylated MET endocytosis in the siRNA-SNX1-transfected gefitinib-resistant human lung cancer cell line. The A549 cells transfected with siRNA-control (si-Ctrl) or siRNA-SNX1 (si-SNX1) were pretreated at $37^{\circ} \mathrm{C}$ for 30 min in the presence of Texas red-transferrin in prewarmed medium. The cells were then incubated with $\mathrm{HGF}(100 \mathrm{ng} / \mathrm{ml})$ at $37^{\circ} \mathrm{C}$ for 30 or 60 min in the presence of bafilomycin A1, and the distribution of internalized phosphorylated MET (pMET) stained with anti-pMET antibody and late endosomes/lysosomes stained with anti-LAMP1 antibody was then assessed by confocal immunofluorescence microscopy after fixation of the cells as described in Materials and methods. Superimposed images of pMET (green) with LAMP1 (red) and pMET (green) with the endocytosed Texas red-labeled transferrin (red) are shown in (A) and (B), respectively. Right column shows the merged images of pMET and LAMP1 staining in (A) or pMET and Texas red-transferrin staining in (B) in the A549 cells transfected with si-Ctrl or si-SNX1, and white squares indicate enlarged regions. 


\section{PMET/LAMP1}

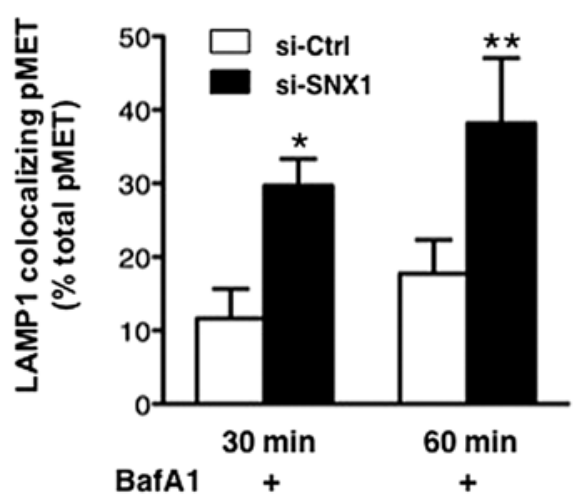

D $\mathrm{pMET} / \mathrm{Tf}$

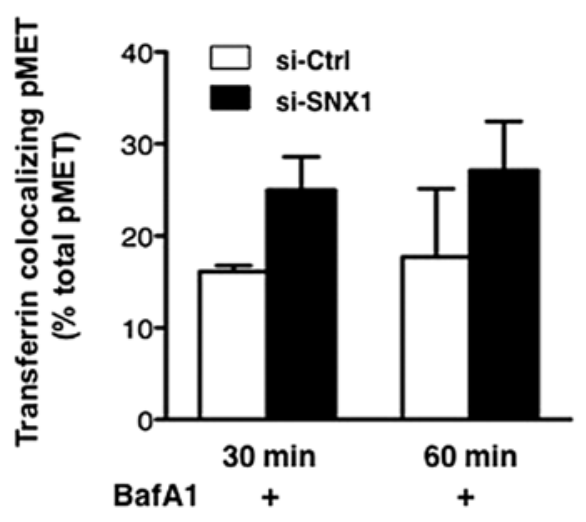

Figure 6. Continued. The long white arrows indicate the merged confocal images as yellow of pMET- and LAMP1-positive staining or pMET- and the endocytosed transferrin-staining in the cells. The colocalization rate between pMET and LAMP1 in the A549 cells transfected with si-Ctrl (white columns) or si-SNX1 (black columns) after 30 or 60 min of HGF stimulation is shown in (C), and the colocalization rate between the pMET and Texas red-labeled transferrin in the A549 cells transfected with si-Ctrl (white columns) or si-SNX1 (black columns) after 30 or 60 min of HGF stimulation is shown in (D). Values are the percentage of the integrated density of LAMP1 or Texas red-labeled transferrin-colocalizing pMET compared to that of total pMET. The error bar denotes SD from three separate experiments, and significance was determined using Student's t-test. Asterisks indicate significant difference between the values $\left({ }^{*} \mathrm{p}<0.05 ;{ }^{* *} \mathrm{p}<0.01\right)$.

endocytosis in the gefitinib-resistant cells. We further found that substantial inhibition of pMET degradation in A549 cells was verified by using bafilomycin A1, a lysosomal inhibitor. Bafilomycin A1 treatment in A549 cells substantially blocked the efficient HGF-induced degradation of pMET, thereby confirming that the HGF-induced pMET is trafficked to late endosomes/lysosomes where extensive degradation for MET protein takes place.

We also showed using western blot analysis that knockdown of SNX1 induced a dramatic increase in the expression of pMET in the siRNA-SNX1-transfected A549 cells and that the observed maximum increase of pMET at $60 \mathrm{~min}$ in the siRNA-SNX1-transfected cells was approximately 1.7-fold higher than that in the siRNA-control-transfected cells. Moreover, the increased amounts of pMET at $60 \mathrm{~min}$ were rapidly degraded within $2 \mathrm{~h}$ in the siRNA-SNX1-transfected cells as compared to that in the siRNA-control-transfected cells. This suggests that intracellular endocytic trafficking followed by downregulation of HGF-induced pMET takes place rapidly via the endosomal/lysosomal pathway in the siRNA-SNX1-transfected cells, whereas considerable amounts of pMET are retained in the early endosomes instead of being delivered to late endosomes/lysosomes for degradation in the siRNA-control-transfected cells. Thus, SNX1 might mediate a negative regulator of $\mathrm{HGF}$-induced $\mathrm{MET} / \mathrm{pMET}$ endocytosis, followed by downregulation via the early/late endosomal pathway. Consequently, we assume that an overexpression of SNX1 in A549 cells suppresses the HGF-stimulated $\mathrm{MET} / \mathrm{pMET}$ endocytic traffic out of early endosomes for targeting the late endosomes/lysosomes where degradation of HGF-MET/pMET proceeds.

We demonstrated recently that in the gefitinib-resistant NSCLC cell line, early endosomes labeled with the endocytosed Texas red-labeled transferrin formed aggregated vesicular structures distributed in the perinuclear region, and that considerable amounts of cytosolic SNX1 were distributed in these aggregated early endosomal vesicles $(26,27)$. Conversely, no such aggregation of SNX1-positive early endosomes was observed in the gefitinib-sensitive NSCLC cell line. Moreover, we showed recently that the transfection of siRNA-SNX1 into the gefitinib-resistant NSCLC cells resulted in an efficient EGFR phosphorylation and a rapid endocytic delivery of pEGFR from early endosomes to late endosomes as revealed by confocal immunofluorescence microscopy. Western blot analysis demonstrated that silencing of SNX1 expression by siRNA in the gefitinib-resistant cells leads to an accelerated degradation of EGFR along with a dramatic increase in the amounts of pEGFR after EGF stimulation (28). On the basis of these data, we postulated that membrane trafficking of pEGFR from early endosomes to late endosomes might be significantly impaired in the gefitinib-resistant NSCLC cells. Therefore, we assume that abrogation of certain components of the SNX1 trafficking machinery could cause this perturbation of EGFR endocytosis, which might lead to the acquisition of gefitinib resistance in NSCLC cell lines.

It was reported that following EGF stimulation, the phosphorylated EGFR is internalized by rapid clathrin-mediated endocytosis, and the internalized EGFR is then sorted via the endosomal-sorting complex required for transport (ESCRT)-dependent pathway for targeting degradation or recycling pathway (18). Consequently, our present data demonstrating the suppressive role of SNX1 in HGF-induced phosphorylation of MET and MET endocytosis is consistent with that in the EGF-stimulated phosphorylation and endocytosis of EGFR via the endocytic pathway in human lung cancer cells. Therefore, it should be noted that SNX1 indeed plays a suppressive role on the HGF-stimulated MET endocytosis and its phosphorylation in the gefitinib-resistant human lung cancer cells. Accordingly, we suggest that SNX1 has a critical function in the maintenance of tightly regulated EGFR- and MET-mediated signaling. It was reported previously that SNX1 interacts with EGFR, and that the overexpression of SNX1 enhanced EGF-dependent EGFR degradation in lysosomes, thereby demonstrating that SNX1 is a likely mediator in the intracellular sorting of EGFR for targeting the lysosomes for degradation (30). In this context, our present data 
A

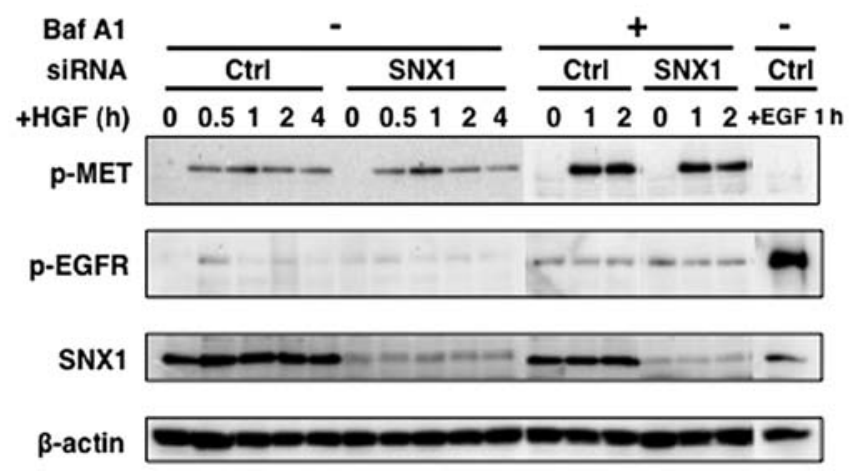

C pEGFR

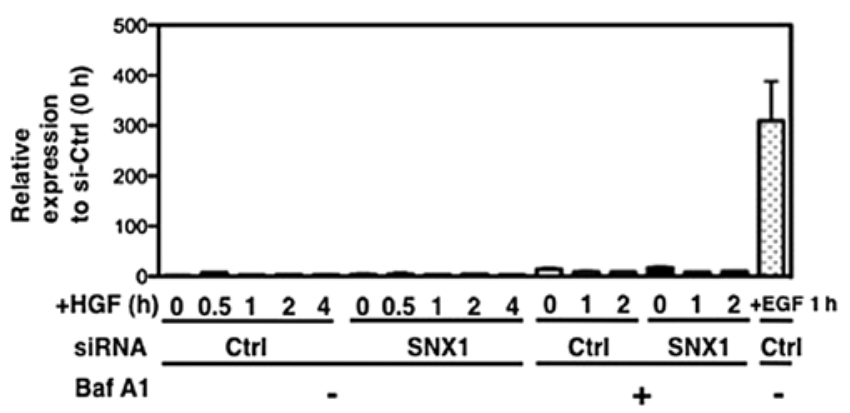

\section{B PMET}

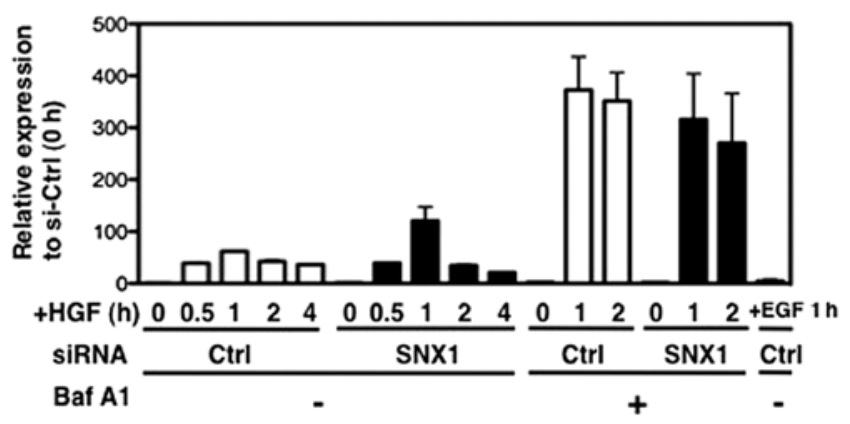

D SNX1

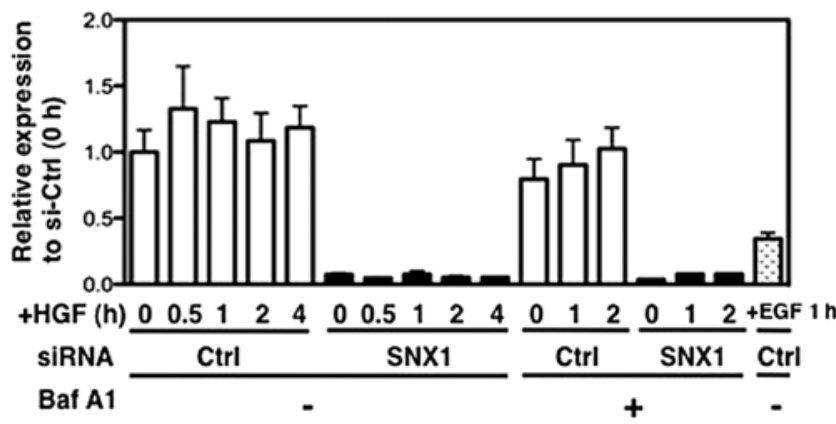

\section{E $\beta$-actin}

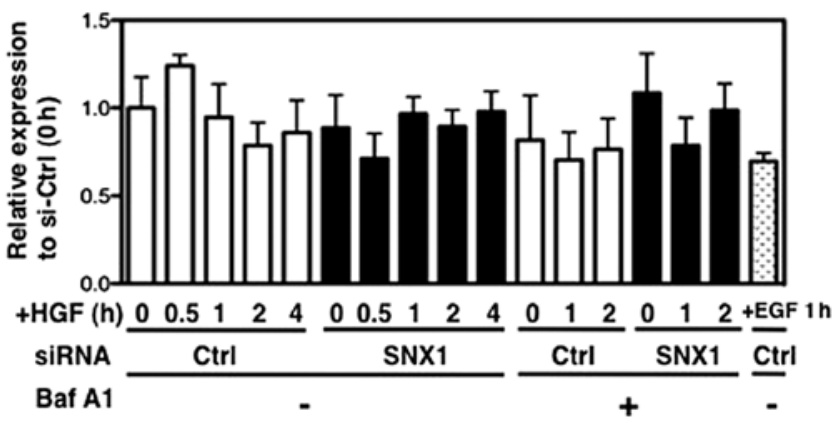

Figure 7. Silencing of SNX1 by siRNA stimulates HGF-induced MET phosphorylation and pMET degradation in the gefitinib-resistant NSCLC cell line. The A549 cells transfected with siRNA-control (si-Ctrl) or siRNA-SNX1 (si-SNX1) were starved for $12 \mathrm{~h}$, followed by incubation with CHX (20 $\mu \mathrm{g} / \mathrm{ml}$ ) and HGF $(100 \mathrm{ng} / \mathrm{ml})$ at $37^{\circ} \mathrm{C}$ in the absence or presence of bafilomycin A1 for the times indicated. In some cases, the A549 cells transfected with si-Ctrl were treated with EGF $(100 \mathrm{ng} / \mathrm{ml})$ at $37^{\circ} \mathrm{C}$ for $1 \mathrm{~h}$. Then cells were lysed, followed by SDS-PAGE and western blot analysis (A) as described in Materials and methods. The amounts of pMET, pEGFR, SNX1 and $\beta$-actin remaining in the cell lysates following HGF or EGF stimulation were quantified using NIH Image software, and were plotted after normalization with $\beta$-actin. Relative expression of (B) pMET, (C) pEGFR, (D) SNX1 and (E) $\beta$-actin in the si-Ctrltransfected cells or si-SNX1-transfected cells is shown. The error bar denotes SD from three separate experiments, and significance was determined using Student's t-test. Note that an increased expression of pMET was seen at 60 min following HGF stimulation in the si-SNX1-transfected cells, as compared to that in the si-Ctrl-transfected cells, and the expression levels of pMET in the siRNA-SNX1-transfected cells was 1.7-fold (at 60 min) higher than that in the siRNA-control-transfected cells. Also the increased pMET was rapidly degraded within $4 \mathrm{~h}$ in the si-SNX1-transfected cells. These results indicate that intracellular degradation of HGF-induced pMET proceeds efficiently via the endosomal/lysosomal pathway in the A549 cells, since large amounts pMET were accumulated in the cells treated with HGF in the presence of bafilomycin A1.

regarding the suppressive action of SNX1 on HGF-stimulated MET endocytosis appear to be in contrast to findings reported previously $(30,31)$.

Engelman et al demonstrated that MET amplification leads to acquired resistance to gefitinib or erlotinib in lung cancer patients by activating ERBB3 signaling (9), and another group reported that MET amplification occurs with or without a representative secondary T790M mutation in EGFR mutant lung tumors with acquired resistance to gefitinib or erlotinib (38). Accordingly, it is reasonable to speculate that depletion of SNX1 leading to the enhanced downregulation of HGF-stimulated MET might affect the sensitivity to EGFR-TKI gefitinib in human NSCLC cells. Further studies to investigate the role of SNX1 on HGF/MET activation and signaling that could affect the EGFR pathway in NSCLC cell lines will be required. 


\section{References}

1. Di Renzo MF, Narsimhan RP, Olivero M, Bretti S, Giordano S, Medico E, Gaglia P, Zara P and Comoglio PM: Expression of the Met/HGF receptor in normal and neoplastic human tissues. Oncogene 6: 1997-2003, 1991.

2. Comoglio PM and Boccaccio C: The HGF receptor family: Unconventional signal transducers for invasive cell growth. Genes Cells 1: 347-354, 1996.

3. Jeffers M, Rong S and Vande Woude GF: Hepatocyte growth factor/scatter factor-Met signaling in tumorigenicity and invasion/metastasis. J Mol Med 74: 505-513, 1996.

4. Pennacchietti S, Michieli P, Galluzzo M, Mazzone M, Giordano S and Comoglio PM: Hypoxia promotes invasive growth by transcriptional activation of the met protooncogene. Cancer Cell 3: 347-361, 2003

5. Kuniyasu H, Yasui W, Kitadai Y, Yokozaki H, Ito $\mathrm{H}$ and Tahara E: Frequent amplification of the c-met gene in scirrhous type stomach cancer. Biochem Biophys Res Commun 189: 227-232, 1992

6. Kijima Y, Hokita S, Yoshinaka H, Itoh T, Koriyama C, Eizuru Y, Akiba S and Aikou T: Amplification and overexpression of c-met gene in Epstein-Barr virus-associated gastric carcinomas. Oncology 62: 60-65, 2002.

7. Nakazawa K, Dobashi Y, Suzuki S, Fujii H, Takeda Y and Ooi A: Amplification and overexpression of c-erbB-2, epidermal growth factor receptor, and c-met in biliary tract cancers. J Pathol 206: 356-365, 2005.

8. Miller CT, Lin L, Casper AM, Lim J, Thomas DG, Orringer MB, Chang AC, Chambers AF, Giordano TJ, Glover TW and Beer DG: Genomic amplification of MET with boundaries within fragile site FRA7G and upregulation of MET pathways in esophageal adenocarcinoma. Oncogene 25: 409-418, 2006.

9. Engelman JA, Zejnullahu K, Mitsudomi T, Song Y, Hyland C, Park JO, Lindeman N, Gale CM, Zhao X, Christensen J, Kosaka T, Holmes AJ, Rogers AM, Cappuzzo F, Mok T, Lee C, Johnson BE, Cantley LC and Jänne PA: MET amplification leads to gefitinib resistance in lung cancer by activating ERBB3 signaling. Science 316: 1039-1043, 2007.

10. Lutterbach B, Zeng Q, Davis LJ, Hatch H, Hang G, Kohl NE, Gibbs JB and Pan BS: Lung cancer cell lines harboring MET gene amplification are dependent on Met for growth and survival. Cancer Res 67: 2081-2088, 2007.

11. Nakamura $\mathrm{T}$, Teramoto $\mathrm{H}$ and Ichihara A: Purification and characterization of a growth factor from rat platelets for mature parenchymal hepatocytes in primary cultures. Proc Natl Acad Sci USA 83: 6489-6493, 1986.

12. Birchmeier $\mathrm{C}$ and Gherardi E: Developmental roles of $\mathrm{HGF} / \mathrm{SF}$ and its receptor, the c-Met tyrosine kinase. Trends Cell Biol 8 : 404-410, 1998

13. Birchmeier C, Birchmeier W, Gherardi E and Vande Woude GF: Met, metastasis, motility and more. Nat Rev Mol Cell Biol 4 915-925, 2003

14. Ullrich A and Schlessinger J: Signal transduction by receptors with tyrosine kinase activity. Cell 61: 203-212, 1990.

15. Rodrigues GA and Park M: Autophosphorylation modulates the kinase activity and oncogenic potential of the Met receptor tyrosine kinase. Oncogene 9: 2019-2027, 1994.

16. Ma PC, Tretiakova MS, Nallasura V, Jagadeeswaran R, Husain AN and Salgia R: Downstream signalling and specific inhibition of c-MET/HGF pathway in small cell lung cancer: Implications for tumour invasion. Br J Cancer 97: 368-377, 2007.

17. Henne WM, Buchkovich NJ and Emr SD: The ESCRT pathway. Dev Cell 21: 77-91, 2011.

18. Yarden Y: The EGFR family and its ligands in human cancer signaling mechanisms and therapeutic opportunities. Eur J Cancer 37: 3-8, 2001.

19. Woodburn JR: The epidermal growth factor receptor and its inhibition in cancer therapy. Pharmacol Ther 82: 241-250, 1999.

20. Baselga J and Averbuch SD: ZD1839 ('Iressa') as an anticancer agent. Drugs 60 (Suppl 1): S33-S42, 2000.

21. Arteaga CL and Johnson DH: Tyrosine kinase inhibitorsZD1839 (Iressa). Curr Opin Oncol 13: 491-498, 2001.

22. Barker AJ, Gibson KH, Grundy W, Godfrey AA, Barlow JJ, Healy MP, Woodburn JR, Ashton SE, Curry BJ, Scarlett L, Henthorn L and Richards L: Studies leading to the identification of ZD1839 (IRESSA): an orally active, selective epidermal growth factor receptor tyrosine kinase inhibitor targeted to the treatment of cancer. Bioorg Med Chem Lett 11: 1911-1914, 2001.
23. Lynch TJ, Bell DW, Sordella R, Gurubhagavatula S, Okimoto RA, Brannigan BW, Harris PL, Haserlat SM, Supko JG, Haluska FG, Louis DN, Christiani DC, Settleman J and Haber DA: Activating mutations in the epidermal growth factor receptor underlying responsiveness of non-small-cell lung cancer to gefitinib. N Engl J Med 350: 2129-2139, 2004.

24. Paez JG, Jänne PA, Lee JC, Tracy S, Greulich H, Gabriel S, Herman P, Kaye FJ, Lindeman N, Boggon TJ, Naoki K, Sasaki H, Fujii Y, Eck MJ, Sellers WR, Johnson BE and Meyerson M: EGFR mutations in lung cancer: correlation with clinical response to gefitinib therapy. Science 304: 1497-1500, 2004.

25. Nishimura Y, Bereczky B and Ono M: The EGFR inhibitor gefitinib suppresses ligand-stimulated endocytosis of EGFR via the early/late endocytic pathway in non-small cell lung cancer cell lines. Histochem Cell Biol 127: 541-553, 2007.

26. Nishimura Y, Yoshioka K, Bereczky B and Itoh K: Evidence for efficient phosphorylation of EGFR and rapid endocytosis of phosphorylated EGFR via the early/late endocytic pathway in a gefitinib-sensitive non-small cell lung cancer cell line. Mol Cancer 7: 1-13, 2008.

27. Nishimura Y, Yoshioka K, Takiguchi S, Bereczky B, Nakabeppu Y and Itoh K: A role for SNX1 in the regulation of EGF-dependent phosphorylated EGFR endocytosis via the early/late endocytic pathway in a gefitinib-sensitive human lung cancer cells. Curr Signal Transduct Ther 6: 383-395, 2011.

28. Nishimura Y, Takiguchi S, Yoshioka K, Nakabeppu Y and Itoh K: Silencing of SNX1 by siRNA stimulates the ligand-induced endocytosis of EGFR and increases EGFR phosphorylation in gefitinib-resistant human lung cancer cell lines. Int J Oncol 41: 1520-1530, 2012.

29. Worby CA and Dixon JE: Sorting out the cellular function of sorting nexins. Nat Rev Mol Cell Biol 3: 919-931, 2002.

30. Kurten RC, Cadena DL and Gill GN: Enhanced degradation of EGF receptors by a sorting nexin, SNX1. Science 272: 1008-1010, 1996.

31. Zhong Q, Lasar CS, Tronchere H, Sato T, Meerloo T, Yeo M, Songyang Z, Emr SD and Gill GN: Endosomal localization and function of sorting nexin 1. Proc Natl Acad Sci USA 99: 6767-6772, 2002

32. Carlton J, Bujny M, Peter BJ, Oorschot VM, Rutherford A, Mellor H, Klumperman J, McMahon HT and Cullen PJ: Sorting nexin-1 mediates tubular endosome-to-TGN transport through coincidence sensing of high-curvature membranes and 3-phosphoinositides. Curr Biol 14: 1791-1800, 2004.

33. Gullapalli A, Garrett TA, Paing MM, Griffin CT, Yang Y and Trejo J: A role for sorting nexin 2 in epidermal growth factor receptor down-regulation: evidence for distinct functions of sorting nexin 1 and 2 in protein trafficking. Mol Biol Cell 15: 2143-2155, 2004

34. Nishimura Y, Higaki M and Kato K: Identification of a precursor form of cathepsin D in microsomal lumen: characterization of enzymatic activation and proteolytic processing in vitro. Biochem Biophys Res Commun 148: 335-343, 1987.

35. Nishimura $Y$, Kawabata $T$ and Kato K: Identification of latent procathepsins $\mathrm{B}$ and $\mathrm{L}$ in microsomal lumen: characterization of enzymatic activation and proteolytic processing in vitro. Arch Biochem Biophys 261: 64-71, 1988.

36. Kornfeld S and Mellman I: The biogenesis of lysosomes. Ann Rev Cell Biol 5: 483-525, 1989.

37. Sandoval IV, Arredondo JJ, Alcalde J, Gonzalez-Noriega A, Vandekerckhove J, Jimenez MA and Rico M: The residues Leu (Ile) 475-Ile (Leu) 476, contained in the extended carboxyl cytoplasmic tail, are critical for targeting of the resident lysosomal membrane protein LIMPII to lysosomes. J Biol Chem 269: 6622-6631, 1994

38. Bean J, Brennan C, Shih JY, Riely G, Viale A, Wang L, Chitale D, Motoi N, Szoke J, Broderick S, Balak M, Chang WC, Yu CJ, Gazdar A, Pass H, Rusch V, Gerald W, Huang SF, Yang PC, Miller V, Ladanyi M, Yang CH, and Pao W: MET amplification occurs with or without T790M mutations in EGFR mutant lung tumors with acquired resistance to gefitinib or erlotinib. Proc Natl Acad Sci USA 104: 20932-20937, 2007. 